\title{
The Role of Knowhow Acquisition in the Formation and Duration of Joint Ventures
}

\author{
Mella-Barral, Pierre ; Habib, Michel A
}

\begin{abstract}
We analyze the role of knowhow acquisition in the formation and duration of joint ventures. Two parties become partners in a joint venture to benefit from each other's knowhow. Joint operations provide each party with the opportunity to acquire part of its partner's knowhow. A party's increased knowhow provides the impetus for the dissolution of the joint venture. We characterize the conditions under which dissolution takes place, identify the party that buys out its partner, determine the time to dissolution, establish its comparative statics, and examine the implications of knowledge acquisition for the desirability of joint venture formation.
\end{abstract}

DOI: https://doi.org/10.1093/rfs/hhl007

Posted at the Zurich Open Repository and Archive, University of Zurich ZORA URL: https://doi.org/10.5167/uzh-63185

Journal Article

Published Version

Originally published at:

Mella-Barral, Pierre; Habib, Michel A (2007). The Role of Knowhow Acquisition in the Formation and Duration of Joint Ventures. Review of Financial Studies, 20(1):189-233.

DOI: https://doi.org/10.1093/rfs/hhl007 


\title{
The Role of Knowhow Acquisition in the Formation and Duration of Joint Ventures
}

\author{
Michel A. Habib \\ Swiss Banking Institute, University of Zurich
}

\author{
Pierre Mella-Barral \\ Department of Finance and Economics, HEC School of \\ Management Paris
}

\begin{abstract}
We analyze the role of knowhow acquisition in the formation and duration of joint ventures. Two parties become partners in a joint venture to benefit from each other's knowhow. Joint operations provide each party with the opportunity to acquire part of its partner's knowhow. A party's increased knowhow provides the impetus for the dissolution of the joint venture. We characterize the conditions under which dissolution takes place, identify the party that buys out its partner, determine the time to dissolution, establish its comparative statics, and examine the implications of knowledge acquisition for the desirability of joint venture formation. (JEL code: G34)
\end{abstract}

Dyer, Kale, and Singh (2004) report that, over the six-year period 19962001, American firms announced 57,000 alliances. ${ }^{1}$ Dyer et al. do not distinguish between equity joint ventures and other forms of alliances, but even a small proportion of joint ventures among the 57,000 alliances announced would amount to a large number such ventures. ${ }^{2}$ Of these, Bleeke and Ernst (1995) suggest that a majority will be dissolved. Our purpose in this paper is to understand the process of joint venture formation and dissolution, and to obtain an estimate of joint venture duration. We consider in particular the role of knowhow acquisition.

The acquisition of knowhow appears to be a central aspect of joint ventures. McConnel and Nantell (1985, Table I) report the findings of a questionnaire administered by Berg and Friedman (1977) regarding the motives for joint

\footnotetext{
We thank Ronald Anderson, James Ang, André Betzer, Mike Burkart, Anna Calamia, Denis Gromb, Ulrich Hege, Bart Lambrecht, Erwan Morellec, Maurren O'Hara (the editor), Ernst Ludwig Von Thadden, two anonymous referees, and seminar participants at the universities of Frankfurt, Cologne, Constance, Lausanne, LBS, LSE, Oxford, St. Gallen, and Zurich, the EFMA meetings in Basel and the Real Options Group Meetings in Montreal for helpful comments. Habib wishes to thank NCCRFINRISK and URPP Finance and Financial Markets for financial support. We are responsible for all errors. Address correspondence to: Swiss Banking Institute, University of Zurich, Plattenstrasse 14, 8032 Zurich, Switzerland, or e-mail: habib@isb.unizh.ch.

${ }^{1}$ This is to be compared with the 74,000 acquisitions announced over the same period of time.

${ }^{2}$ An equity joint venture is a specific form of alliance that involves the creation of a new entity in which the two or more firms entering into the alliance hold equity stakes. Alliances, whether equity- or non-equity based, differ from mergers and acquisitions in that the firms involved retain their separate identities in the former case but not the latter.
}

(C) The Author 2006. Published by Oxford University Press on behalf of The Society for Financial Studies. All rights reserved. For permissions, please email: journals.permissions@oxfordjournals.org. 
ventures. "To acquire skills and technical knowhow" is ranked first among ten different motives such as "to acquire distribution facilities" (ranked second), "to acquire capital" (ranked seventh), or "to exploit a product or a licensed process" (ranked tenth). More recently, Doz and Hamel (1998, p. 5) write that "alliances may [...] be an avenue for learning and internalizing new skills, in particular those which are tacit, collective and embedded (and thus hard to obtain and internalize by other means)."

We examine the implications of knowhow acquisition for the formation and duration of joint ventures. Our concern is with the circumstances in which the desire for knowhow acquisition may lead two firms to enter into a joint venture. Following the formation of the venture, we wish to determine whether there may be a point at which one or both firms may decide that enough knowhow has been acquired for the joint venture no longer to be necessary. The decision to dissolve the joint venture clearly is affected by the contract that regulates exit from the venture. We derive the properties of an optimal exit contract. We note that, where the desire to combine knowhow provides the impetus for the joint venture, the acquisition of knowhow may nonetheless occur and therefore affect the decision to dissolve the venture. ${ }^{3}$

The problem we consider is one deemed of great importance by students of joint ventures. To take an admittedly extreme example, Reich and Mankin (1986) once argued that "joint ventures with Japan give away our future." More recently, Hamel (1991) raised the possibility of "learning races" between partners in a joint ventures. The partners' awareness that knowhow affects bargaining power induces the partners to increase their knowhow by decreasing the "transparency" of their own knowhow to their partner and increasing their "receptivity" to their partner's knowhow. Following Hamel, many papers have considered the implications of learning for what has been called the stability of joint ventures. ${ }^{4}$ However, as these papers generally have not presented a formal model of learning in joint ventures, it has been difficult to derive precise testable implications from the papers. For example, in their analysis of international joint ventures between a foreign partner and its local counterpart, Inkpen and Beamish (1997) assume that learning favors the foreign partner, in the sense that learning should eventually allow that partner to operate the venture alone. We make no such assumption. Instead, we derive the identity of the partner who buys out its counterpart at dissolution from the primitives of our model.

\footnotetext{
${ }^{3}$ The combination of knowhow is not the same as the acquisition of knowhow. The former increases the knowhow available to the partners in a joint venture, the latter increases the knowhow available to each partner should the joint venture be dissolved.

${ }^{4}$ See for example Ariño and de la Torre (1998), Doz (1996), Inkpen and Beamish (1997), Khanna, Gulati, and Nohria (1998), and Makhija and Ganesh (1997).
} 
More specifically, we examine a situation in which there are two firms and one asset. We consider the conditions under which a joint venturewhich involves the joint operation of the asset by the two firms-is formed. The alternative to the joint venture is the separate operation of the asset by a single firm. In case a joint venture is formed, we examine the dynamics of the venture and the increase in each partner's knowhow through learning from the other partner. Such learning decreases the incremental benefit from having the partners join forces. It may then become profitable for the joint venture to be dissolved and for one partner to buy out the other and operate the asset alone. On that reading, and as noted by Reuer (2001), the dissolution of a joint venture is not a failure attributable to the parent companies' inability to cooperate, but an efficient adaptation to a changed situation. It is anticipated at the outset. ${ }^{5}$

We construct a continuous time model that allows us to characterize the conditions under which dissolution takes place, to identify the party that buys out its partner at dissolution, to determine the time to dissolution, to establish its comparative statics and to examine the implications of knowledge acquisition for the desirability of joint venture formation.

We find that every joint venture is temporary, in the sense that there comes a time at which the joint venture is dissolved. Compared with the separate operation of the asset by a single firm, the joint operation of the asset in a joint venture brings benefits and entails costs. A crucial benefit is the opportunity the joint venture offers each partner to acquire the knowhow of the other partner. As each partner's knowhow increases, so does the partner's ability to operate the asset separately. The relative benefit of joint operations over separate operations consequently decreases. It eventually disappears altogether. As the costs of joint operations are unaffected, there comes a time at which the joint venture is dissolved.

There are two costs to joint operations. These costs are associated with double moral hazard and with the discrepancy in the partners' costs. Double moral hazard denotes a partner's concern with the value of its own stake in the venture rather than the value of the entire venture. Double moral hazard gives rise to the first cost of joint operations, for it decreases a partner's contribution to the venture below what it would be if the partner were to operate the venture alone, all else being equal. The second cost of joint operations is that, where there is a discrepancy in the partners' costs, there is a cost to having resources

\footnotetext{
${ }^{5}$ A similar point is made by Fluck and Lynch (1999), who consider the succession of a merger and a divesture. A conglomerate merger creates financial synergies that make possible the financing of a marginally profitable project that cannot be financed by a stand-alone firm because of agency problems. Where the project is successful, agency considerations are no longer a concern, and the project is divested because of coordination costs. For evidence that divesture need not signify failure, see Kaplan and Weisbach (1992).
} 
contributed by both partners rather than by the low-cost partner alone. $^{6}$

We establish the identity of the superior user of the asset at the time of optimal dissolution. The profitability of a partner's use of the asset depends on the partner's cost and on the partner's knowhow. For the high-cost partner to be the superior user of the asset at dissolution, the partner's higher cost must be compensated by that same partner's higher knowhow. This is unlikely when the joint venture has been operating for a long time, for the low-cost partner then has acquired most of the knowhow of its high-cost counterpart. It is more likely when the joint venture is dissolved shortly after having been formed.

In the absence of moral hazard, we show that the superior user at dissolution is always the low-cost partner. This is because the second cost of joint operations, which arises from the discrepancy in the partners' costs, is compounded rather than alleviated by buyout by the high-cost partner. Following such buyout, all resources would be contributed by the high-cost partner alone, rather than jointly by the high-cost partner and the low-cost partner. Consequently, in the absence of moral hazard, the joint venture will not be dissolved before the low-cost partner has become the superior user of the asset.

In contrast, when we allow for moral hazard, we find that the superior user of the asset at dissolution is no longer necessarily the low-cost partner. It may instead be the high-cost partner. This is because the cost of moral hazard may be so high as to warrant dissolution at a time when the low-cost partner has not yet become the superior user of the asset. Buyout by the high-cost partner compounds the cost of the discrepancy in costs, but it alleviates the cost of moral hazard.

We find no evidence of learning races between the partners. Why this is so can perhaps most easily be understood in the case where the low-cost partner buys out its high-cost counterpart at dissolution. The joint venture may then be viewed as an arrangement through which the high-cost partner transmits its knowhow to its low-cost counterpart to capitalize on the counterpart's low cost. ${ }^{7}$ Because the high-cost partner will be bought out at a price that reflects both the cost advantage of the low-cost partner and the knowhow it has acquired from the high-cost partner, it is actually in the interest of the high-cost partner to transmit its knowhow. ${ }^{8}$ Nonetheless, to the extent the partners expect to bargain over the price at which

\footnotetext{
${ }^{6} \mathrm{We}$ assume that the cost of operating the asset is unaffected by the acquisition of knowhow.

${ }^{7}$ We thank an anonymous referee for suggesting this view of the joint venture to us.

${ }^{8}$ In the case where it is the high-cost partner that buys out its low-cost counterpart, a similar process is at work, but the partners then wish to capitalize on the high-cost partner's greater ease of knowhow acquisition. Although extending the duration of the venture would eventually see the low-cost partner replace its high-cost counterpart as superior user of the asset, joint operations are costly and are in the present case optimally dissolved, before the low-cost partner has become the superior user of the asset.
} 
the low-cost partner is bought out, or over the date at which the joint venture is dissolved, they may seek to speed up learning to improve their default positions in negotiation, that is, engage in learning races. Learning for the purpose of improving bargaining position in negotiation is best avoided, for it decreases the joint payoff of the partners. We derive an optimal exit contract that makes the terms of dissolution renegotiation proof and thereby precludes learning races. This contract is reminiscent of the "cake-cutting mechanism," a mechanism whereby one partner specifies a price at which the other partner can either buy out the first partner or sell out to the first partner.

Our finding of no evidence of learning races is somewhat unexpected, given the importance attached such races by Hamel (1991) and others. It is, however, consistent with recent empirical findings by Hennart, Roehl, and Zietlow (1999), who have questioned whether learning races do in fact occur. In our model, and as noted above, learning races are precluded by introducing an exit contract that makes the terms of dissolution renegotiation proof. The desire to avoid learning races may therefore account for the importance attached exit clauses in joint venture contracts. ${ }^{9}$

Summarizing, we find that (i) joint ventures are necessarily temporary in nature; (ii) there are no learning races where optimal contracts are used; (iii) the duration of a joint venture depends on the discrepancy in the partners' costs, the extent of moral hazard, the buying partner's ease of knowhow acquisition and the amount of knowhow to be acquired; (iv) dissolution may take place before all knowhow has been acquired; (v) the identity of the buying partner at dissolution is determined by the extent of moral hazard and the ease of knowhow acquisition; (vi) the identity of the buying partner is related to the duration of the venture; (vii) the optimal exit contract reduces to a modified form of the cake-cutting mechanism and (viii) dissolution need not imply failure; indeed, dissolution may mark the success of the venture in achieving the desired transfer of knowhow.

For example, consider the aircraft engine joint venture between BMW and Rolls-Royce. ${ }^{10}$ The venture lasted 10 years and ended in 1999 with the buyout of BMW by Rolls-Royce. While it is possible that the venture ended because of a failure to cooperate on the part of the two partners, such an explanation is unlikely given that BMW was paid in Rolls-Royce shares, which have made BMW one of the largest shareholders of Rolls-Royce,

\footnotetext{
${ }^{9}$ Besides the cake-cutting mechanism, other exit clauses are put and call options and, in case a third party is involved, drag-along, tag-along, and pre-emption rights. For a discussion of these and other clauses in joint venture and venture capital contracts, see Chemla, Habib, and Ljungqvist (2004) and Fluck, Garrison, and Myers (2005).

${ }^{10}$ We note that there is a difference between Rolls-Royce the aircraft engine manufacturer and Rolls-Royce the car manufacturer. Our concern here is with the former.
} 
with a $10 \%$ stake. A more likely explanation in our view is that Rolls-Royce, which long ago had stopped manufacturing small aircraft engines, wished to reenter that business and believed it could prof it from BMW's small engines knowhow for that purpose. Once Rolls-Royce had acquired sufficient small engine knowhow from BMW, there was no longer a need for the joint venture. BMW was willing to enter into the joint venture and communicate its small engine knowhow to Rolls-Royce because the joint venture provided BMW with an additional means through which to profit from such knowhow. According to our explanation, that Rolls-Royce bought out BMW rather than the converse was to be expected. Rolls-Royce is an aircraft engine company, whereas BMW is a car company. The cost to Rolls-Royce of operating a small aircraft engine business should therefore be much lower than to BMW.

The available empirical evidence appears to be consistent with our analysis, at least in so far as the dissolution of joint ventures is concerned. Kogut (1991) considers 92 joint ventures formed over the 9-year period 1975-1983. He finds that, at the time of his writing, approximately 10 years later than the midpoint of the period 1975-1983, 27 such ventures were terminated by liquidation and 37 by acquisition. These 64 dissolutions amount to nearly $70 \%$ of the joint ventures that were formed. Kogut (1991) does not, however, distinguish between acquisition by one partner and acquisition by a third party. Hauswald and Hege (2003) do. They consider 151 US joint ventures by two publicly traded parents that were terminated during the period 1985 to 2000 . They find that 92 (61\%) joint ventures were terminated by a complete buyout of one partner by the other, $7(5 \%)$ were acquired by third parties and $52(34 \%)$ were liquidated.

Our article is in the line of a relatively recent but rapidly growing literature that has applied continuous time methods to corporate finance problems. ${ }^{11}$ The main emphasis of this literature has been on explaining observed leverage ratios and corporate bond spreads. ${ }^{12}$ More recently, the literature has been extended to analyze the pricing of venture capital and of sovereign debt. ${ }^{13}$ It has also been extended to analyze agency issues and merger dynamics. ${ }^{14}$ Our paper continues this process by applying continuous time techniques to the analysis of the dynamics of joint ventures. As such, the paper extends the static approach to joint ventures generally found in the economics literature. This literature has examined

\footnotetext{
${ }^{11}$ For a nice survey of continuous time methods in finance, see Sundaresan (2000).

${ }^{12}$ See for example Anderson and Sundaresan (1996), Collin-Dufresne, Goldstein, and Martin (2001), Fan and Sundaresan (1999), Hackbarth, Hennessy, and Leland (2004), Leland (1994, 1998), Leland and Toft (1996), Mella-Barral (1999), and Mella-Barral and Perraudin (1997).

${ }^{13}$ For the former, see for example Berk, Green, and Naik (2004). For the latter, see Chang and Sundaresan (2001).

${ }^{14}$ For the former, see for example Morellec (2004). For the latter, see Lambrecht (2004), Leland and Skarabot (2003), and Morellec and Zhdanov (2005).
} 
the rationale for joint venture formation, and has related the characteristics of the venture to those of the partners and the environment, but it has not considered the evolution of the joint venture over time. ${ }^{15}$

Two exceptions to the static approach found in the economic literature are Kogut (1989) and Kogut (1991). These two article are primarily empirical in nature. The first article relates the hazard rate of a venture to the partners' ability to maintain the collusive behavior required by the venture through dealings external to the venture, such as supply and other contracts. The second article views a joint venture as an option to acquire and relates the hazard rate of the venture to an improvement in industry conditions that increases the moneyness of the option, thereby inducing the optionholder to exercise the option to buy out its counterpart. We do not consider the former issue and rely instead on the partners' equity stakes in the venture to provide them with the requisite incentives. We explicitly model the learning that is implicit in Kogut's (1991) empirical analysis and extend such learning from one-sided learning about industry prospects to two-sided learning about partners' knowhow. ${ }^{16}$

We proceed as follows. We present the model in Section 1. We examine the case of separate operations in Section 2. We examine the case of joint operations in the absence of moral hazard in Section 3 and in its presence in Section 4. In Section 5, we compare the two forms of organization for the purpose of determining the form chosen at the outset. We compute the duration of the joint venture in Section 6. We provide a numerical example in Section 7. We discuss the costs of moral hazard in Section 8. We provide some empirical evidence and testable implications in Section 9. We conclude in Section 10.

\section{The Model}

Consider two firms $a$ and $b$ and one asset. Starting at the initial date $t=0$, the asset may be operated separately by a single firm or jointly by the two firms cooperating in a joint venture. Regardless, the asset may become worthless because of an exogenous shock at some random date $\bar{t}$.

\footnotetext{
${ }^{15}$ For an analysis of joint ventures and strategic alliances, see Allen and Phillips (2000), Belleflamme and Bloch (2000), Bhattacharyya and Lafontaine (1995), Bruner (1999), Chan et al. (1997), Darrough and Stoughton (1989), Elfenbein and Lerner (2003), Gomes and Novaes (2001), Hauswald and Hege (2003), Holmström (1982), Johnson and Houston (2000), Legros and Matthews (1993), McConnell and Nantell (1985), Mohanram and Nanda (1998), Noe, Rebello, and Shrikhande (2002), Oxley (1997), Pisano (1989), Rey and Tirole (1998), Sampson (2004), and Van den Steen (2002).

${ }^{16}$ An important exception to the static approach found in the economic literature on joint ventures is provided by the theoretical literature on research joint ventures [see Muennich (2000) for a survey]. Research joint ventures are inherently dynamic, in that they are formed for the specific purpose of conducting some joint research and are dissolved upon completion of that research. The literature on research joint ventures has taken the dissolution time as given. It therefore does not address the issues of whether a joint venture will be dissolved and, if so, when. Our analysis addresses these issues.
} 
If this happens, the asset is best liquidated. The separate operation of the asset by firm $i, i \in\{a ; b\}$, yields instantaneous revenue at date $t \in[0 ; \bar{t}]$

$$
R\left(e_{i}, k_{i}(t)\right)=e_{i}^{\gamma} k_{i}(t)^{1-\gamma},
$$

at instantaneous cost

$$
C_{i}\left(e_{i}\right)=\omega_{i} e_{i},
$$

where $e_{i} \in \mathbf{R}^{+}$denotes the resources contributed to the asset by firm $i$ at the start of separate operations, $k_{i}(t) \in \mathbf{R}^{+*}$ denotes firm $i$ 's knowhow at date $t, \gamma \in(0,1)$ indexes the importance of the resources contributed relative to that of knowhow and $\omega_{i} \in \mathbf{R}^{+*}$ denotes the cost of a unit of resources contributed by firm $i$. For example, the asset may be a plant or a research laboratory, the resources contributed may be engineers or scientists, $\gamma$ indexes the importance of the engineers or the scientists' role relative to that of the knowhow embedded in the firm's processes and procedures, and $\omega_{i}$ represents the opportunity cost to the firm of contributing the engineers and the scientists to the plant or the research laboratory.

The liquidation date $\bar{t}$ is modeled as a stopping time with constant intensity $\lambda \in \mathbf{R}^{+*}$. This essentially means that, at any date $t<\bar{t}$, the probability of liquidation before $t+\Delta$ is approximately $\lambda \Delta$. This simple modeling of liquidation assumes that the stopping time has stochastic arrival intensity. ${ }^{17}$ The stopping time may be the time at which a new technology appears, that renders worthless the asset, the resources, and the knowhow. It is then best immediately to stop operations and liquidate the venture.

We now consider the joint operation of the asset by the two firms, now partners in a joint venture. The joint operation of the asset yields instantaneous revenue at date $t \geq 0$

$$
R_{J}(\mathbf{e})=s(\mathbf{e})^{\gamma} \bar{k}^{1-\gamma},
$$

where

$$
s(\mathbf{e})=\left(\delta_{a}^{\delta_{a}} \delta_{b}^{\delta_{b}}\right)^{-1} e_{a}^{\delta_{a}} e_{b}^{\delta_{b}} .
$$

The vector $\mathbf{e} \equiv\left(e_{a}, e_{b}\right)$ denotes the resources contributed by the two partners at the start of joint operations, the constant $\delta_{i} \in(0,1)$ indexes

\footnotetext{
${ }^{17}$ Artzner and Delbaen (1989), Lando (1994), and Jarrow and Turnbull (1995) introduced this modeling device to the pricing of defaultable bonds.
} 


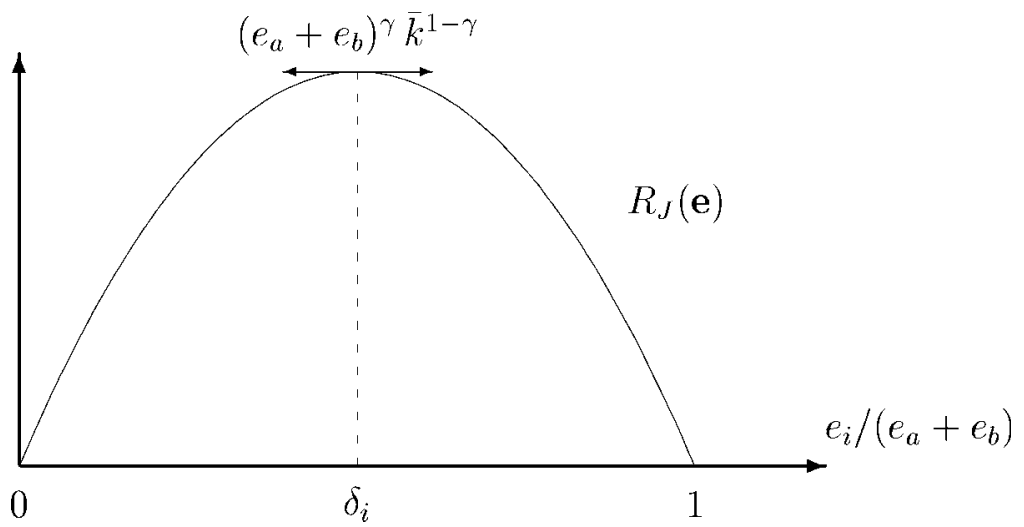

Figure 1

Revenues from Joint Operations $R_{J}(\mathrm{e})$

the relative importance of partner $i$ 's contribution, $\delta_{a}+\delta_{b}=1$, and the constant $\bar{k} \in \mathbf{R}^{+*}$ denotes the two firms' combined knowhow, with $\bar{k} \leq k_{a}(0)+k_{b}(0)$. The strict inequality $\bar{k}<k_{a}(0)+k_{b}(0)$ corresponds to the case where there is some overlap between the initial knowhows of the two firms. By analogy to the vector $\mathbf{e}$, we let the vector $\mathbf{k}(t) \equiv\left(k_{a}(t), k_{b}(t)\right)$ denote the partners' knowhow at date $t$. To continue with the example above, $\delta_{a}$ and $\delta_{b}$ index the relative importance of the engineers or scientists contributed to the venture by partners $a$ and $b$, respectively.

We note that the combination of knowhow in the joint venture $(\bar{k}$ vs. $\left.k_{i}(t)\right)$ can be viewed as making possible increased revenues (e.g., from cross-selling), decreased costs (e.g. from the adoption of more efficient production techniques), or both. ${ }^{18}$

The factor $\left(\delta_{a}^{\delta_{a}} \delta_{b}^{\delta_{b}}\right)^{-1}$ in (4) ensures that combining knowhow only increases revenues when the two partners do not have the same knowhow. When $\bar{k}=k_{a}(0)=k_{b}(0)$, revenues are equal in the case where a single firm operating the asset alone contributes resources $\bar{e}$ and in that where each of two partners jointly operating the asset contributes resources $e_{i}=\delta_{i} \bar{e}^{19}$ Figure 1 plots $R_{J}(\mathbf{e})$ as a function of partner $i$ 's relative contribution.

${ }^{18}$ More formally, introducing the notation, $r_{i}(t), c_{i}(t), \bar{r}$, and $\bar{c}$, such that $k_{i}(t)=r_{i}(t)-c_{i}(t)$ and $\bar{k}=\bar{r}-\bar{c}$, the overall impact of combining knowhow consists of an impact on gross revenues $\left(\bar{r}\right.$ vs. $\left.r_{i}(t)\right)$ and an impact on costs $\left(\bar{c}\right.$ vs. $\left.c_{i}(t)\right)$. The revenues $R($.$) and R_{J}($.$) should therefore be viewed as net revenues, or$ EBIT.

${ }^{19}$ The contribution of resources in the proportions $\delta_{a}$ and $\delta_{b}$ is optimal in the sense of maximizing revenues for a given level of total resource contributions. In other words, for a given $\bar{e}=e_{a}+e_{b}, R_{J}(\mathbf{e})$ is maximized when $e_{a} / \bar{e}=\delta_{a}$ and $e_{b} / \bar{e}=\delta_{b}$. 


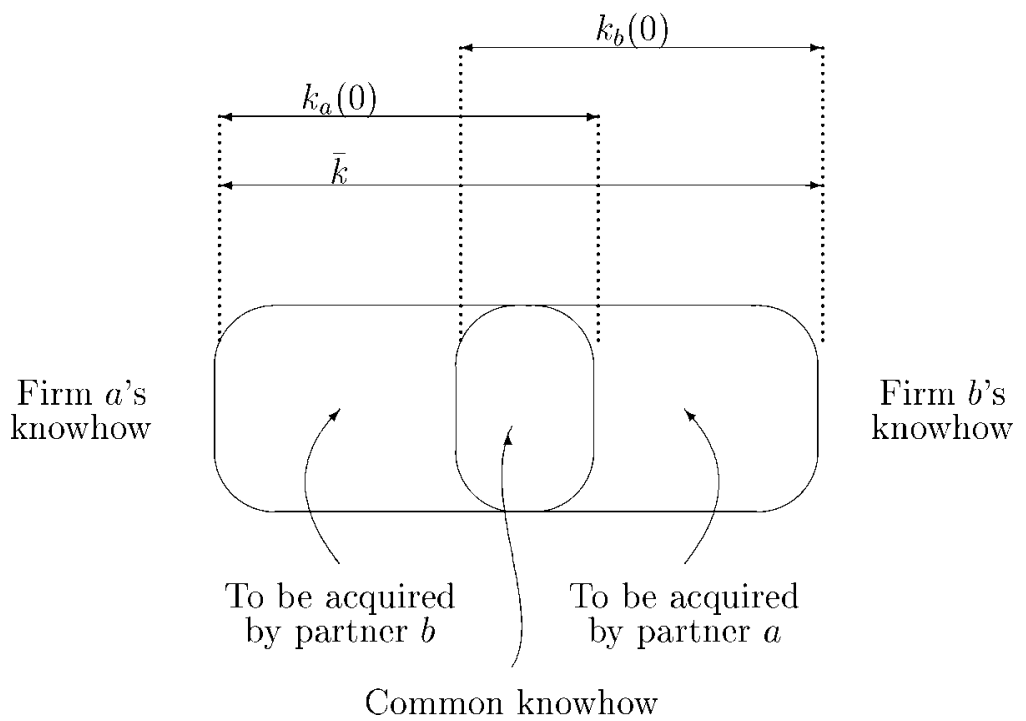

Figure 2

Firms' initial knowhow, $\left(k_{a}(\theta), k_{b}(0)\right)$, Combined Knowhow, $\bar{k}$, and Knowhow to be Acquired

The cost to firm $i$ of contributing resources $e_{i}$ is unaffected by how the asset is operated: it is $C_{i}\left(e_{i}\right)$ in either case.

We assume joint operation in a joint venture to be the only channel through which knowhow can be acquired and that each partner acquires the other partner's knowhow. Thus, the two partners' combined knowhow, $\bar{k}$, remains constant throughout, and each firm's knowhow $k_{i}(t)$ remains constant under separate operations. Figure 2 shows the relation between the initial knowhow of a partner, the knowhow the partner can potentially acquire in the joint venture, and the partners' combined knowhow.

A firm's knowhow at any point in time is therefore the sum of its initial knowhow and the knowhow it gained while in a joint venture ${ }^{20}$

$$
k_{i}(t)=k_{i}(0)+g_{i}(t) .
$$

The conditions we impose on the gain function, $g_{i}(t)$, are intended to reflect the following:

\footnotetext{
${ }^{20}$ This is a form of learning-by-doing. For an application of learning-by-doing to the related field of venture capital, see Bergemann and Hege (2005).
} 
(i) A partner's knowhow never decreases; hence, the gain in knowhow is an increasing function of time. That is, $d g_{i}(t) / d t \geq 0$.

(ii) A partner's knowhow does not jump through time; hence, the gain in knowhow is a continuous function of time.

(iii) A partner's knowhow initially equals $k_{i}(0)$; hence, the gain in knowhow initially equals zero. That is, $g_{i}(0)=0$.

(iv) A partner's knowhow is at most equal to the two partners' combined knowhow, $\bar{k}$; hence, the knowhow gained by a partner is at most equal to the difference between the partners' combined knowhow and that same partner's initial knowhow. That is, $\lim _{t \rightarrow+\infty} g_{i}(t)=\bar{k}-k_{i}(0)$.

(v) The acquisition of knowhow is uncertain; hence, the gain in knowhow is an increasing function of a stochastic state variable, $x(t)$, that reflects how favorable are learning conditions within the joint venture.

(vi) A partner's gain in knowhow depends on the ease with which that partner acquires its counterpart's knowhow; hence, the gain in knowhow is an increasing function of a parameter, $f_{i} \in \mathbf{R}$, that indexes the ease with which knowhow may be acquired.

(vii) A partner's knowhow is constant under separate operations; hence, the gain in knowhow is constant under separate operations. That is, $d g_{i}(t) / d t=0$ under separate operations.

A simple functional form that reflects the preceding conditions is ${ }^{21}$

$$
g_{i}(t)=\left(\bar{k}-k_{i}(0)\right)\left[\frac{x(t)-1}{x(t)-f_{i}}\right] .
$$

Condition (v) requires that $f_{i}<1 .{ }^{22}$ Condition (iii) requires that $x(0)=1$. To satisfy conditions (i), (ii), (iv), and (vii), we take the learning conditions state variable, $x(t)$, to be the historical maximum of an upward drifting geometric Brownian motion, $y(t)$, over the interval of time, $T_{J}(t)$, during which the joint venture has been in operation at date $t$

$$
x(t) \equiv \max _{\tau \in \mathcal{T}_{J}(t)}\{y(\tau)\}
$$

where

\footnotetext{
${ }^{21}$ In addition, the functional form (6) delivers closed form solutions and finite resource contributions.

${ }^{22}$ Knowhow is acquired most easily as $f_{i} \rightarrow 1$. It is acquired least easily as $f_{i} \rightarrow-\infty$.
} 


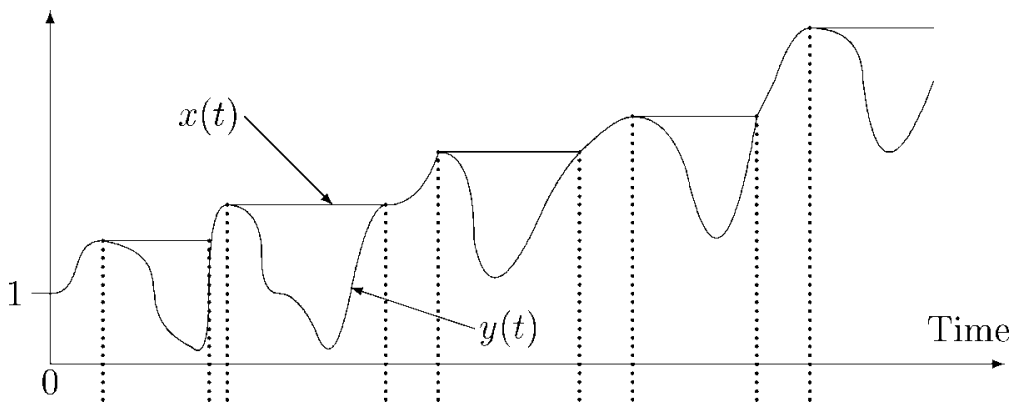

Figure 3

Learning Uncertainty Factor, $x(t)$

$$
d y(t)=\mu y(t) d t+\sigma y(t) d B(t),
$$

$y(0)=1,(\mu, \sigma) \in \mathbf{R}^{+*} \times \mathbf{R}^{+*}$, and $B(t)$ denotes a standard Brownian motion. We further assume that $y(t)$ is constant under separate operations. ${ }^{23}$

Figures 3 and 4 show how (7) affects the gain in knowhow and the knowhow itself by (6) and (5), respectively. Firms gain knowhow but do not lose it. They do not gain knowhow over some periods of time. Figure 5 shows firm $i$ 's knowhow as a function of the ease of knowhow acquisition, $f_{i}$, and firm $i$ 's initial knowhow, $k_{i}(0)$.

As a firm acquires knowhow through the joint operation of the asset, the firm increases the profitability of its separate operation of the asset. A phase of joint operations therefore makes separate operations more desirable than was the case at the start of joint operations. Should the joint venture eventually be dissolved, the separate operation of the asset by firm $i$ yields instantaneous revenue $R\left(\hat{e}_{i}, k_{i}(\hat{t})\right)$ at instantaneous cost $C_{i}\left(\hat{e}_{i}\right)$ at date $t \geq \hat{t}$. Here, $\hat{e}_{i} \in \mathbf{R}^{+}$denotes the resources contributed by firm $i$ at the date $\hat{t}$ at which the joint venture is dissolved and separate operations are initiated.

In the case where separate operations entail the sale of the asset from its original owner to its best user, firms $a$ and $b$ can be expected to bargain over the sale price of the asset. In the case of joint operations, the original owner of the asset naturally expects to be compensated for bringing the asset into the joint venture. Besides the asset itself, the partners make contributions that differ in their relative importance to the venture. The partners can therefore be expected to bargain over a transfer payment

\footnotetext{
${ }^{23}$ This ensures that, in accordance with condition (ii), there is no jump in knowhow in case joint operations should start at date $t>0$.
} 


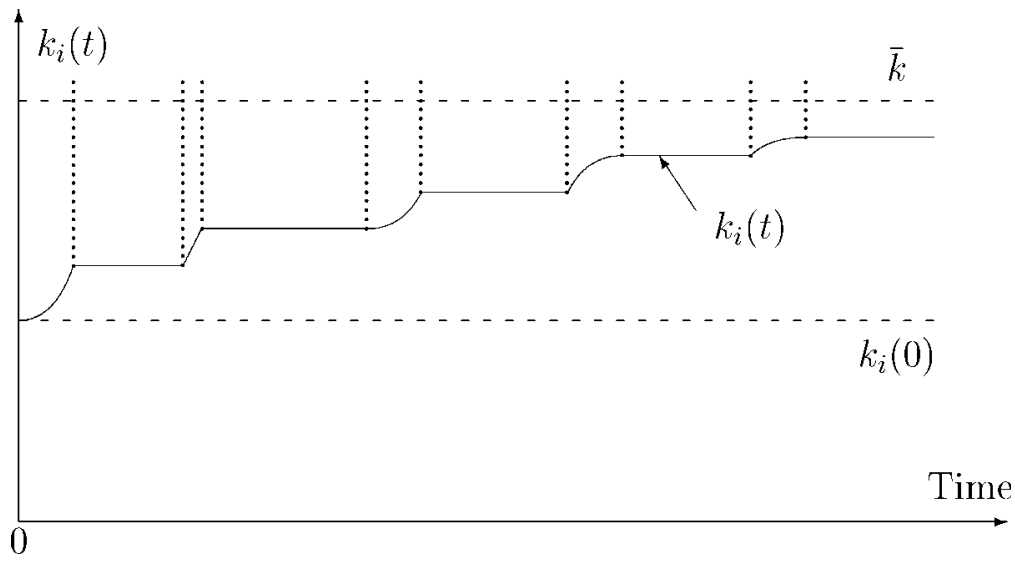

Figure 4

Evolution of Firm $i$ 's Knowhow, $\boldsymbol{k}_{i}(t)$

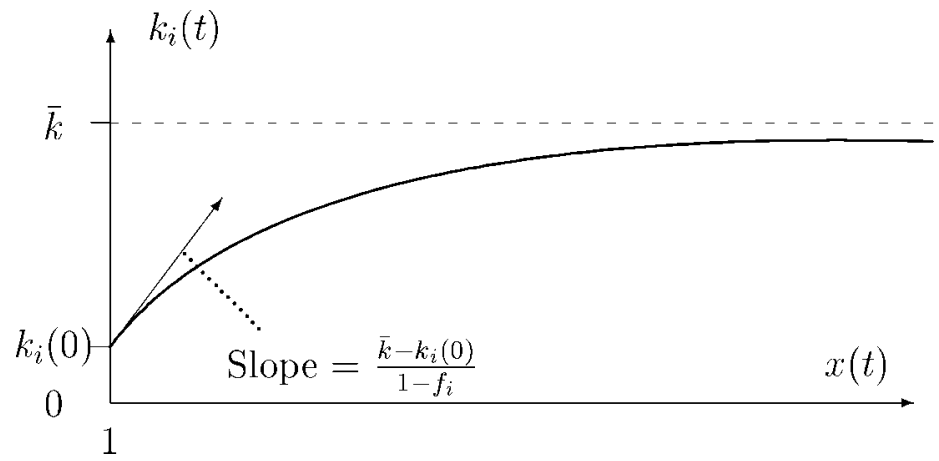

Figure 5

Evolution of Firm $i$ 's Knowhow, $\boldsymbol{k}_{i}(\boldsymbol{t})$

intended to establish a balance between the partners' contributions to the venture and their share of the gains from the venture. We assume costless bargaining between the parties. We adopt the generalized Nash bargaining solution, and denote $\beta_{i}, 0 \leq \beta_{i} \leq 1$, the bargaining power of firm $i, \beta_{a}+\beta_{b}=1 .^{24} \mathrm{We}$ assume all payments are made in cash and are verifiable.

In case joint operations should at some point be abandoned for separate operations, the superior user of the asset should buy out its 'inferior' counterpart. In the absence of an exit contract, the payment made by the

\footnotetext{
${ }^{24}$ For a discussion of the Nash bargaining solution, see, for example, Myerson (1997).
} 
former to the latter, and possibly the time at which to dissolve the venture, would be left to negotiation. Such negotiation is best avoided. The bargaining that accompanies negotiation between the partners over and at the time the joint venture is dissolved can be expected to distort the partners' choices (e.g., Hart, 1995). We therefore solve for an exit contract that achieves a renegotiation-proof equilibrium. Thus, although our model allows for negotiation over both the time of dissolution and the price to be paid at such time, the exit contract we derive is such as to deny the partners the incentives to engage in such negotiation. ${ }^{25}$

Throughout, we assume that there are no asymmetries of information, that capital markets are frictionless, that agents are risk neutral, and that they may borrow and lend freely at the constant, risk-free rate of interest, $r_{0} \in \mathbf{R}^{+*}$.

In the sections that follow, we shall analyze the determinants of the formation and duration of joint ventures. We first examine the value of the asset under separate and joint operations. We then compare these values for the purpose of determining the form of organization chosen at the outset.

\section{Separate Operations}

We first consider the value of separate operations, assuming they are the organizational form chosen at date $t=0$. Given that knowhow is constant under separate operations, $k_{i}(t)=k_{i}(0)$ for all $t \geq 0$, the value to firm $i$ of operating the asset separately at date $t \geq 0$ is

$$
V_{i, S}\left(k_{i}(0)\right) \equiv \max _{e_{i}}\left\{E_{t}\left[\int_{t}^{+\infty} \exp ^{-r_{0}(\tau-t)}\left[R\left(e_{i}, k_{i}(0)\right)-C_{i}\left(e_{i}\right)\right] 1_{\{\tau<\bar{t}\}} d \tau\right]\right\} .
$$

The factor $1_{\{t<\bar{t}\}}$ is a random variable that is 1 for all dates before the event of liquidation and 0 afterwards. We now establish ${ }^{26}$

Proposition 1. The value to firm $i$ of operating the asset separately at any date $t \geq 0$ is

$$
V_{i, S}\left(k_{i}(0)\right)=\frac{k_{i}(0)}{r}(1-\gamma)\left(\frac{\gamma}{\omega_{i}}\right)^{\frac{\gamma}{1-\gamma}}
$$

\footnotetext{
${ }^{25}$ Our model also allows the partners to renegotiate their shares of the continuing joint venture. However, as we shall see in Section 4.2, the stationary nature of the problem implies that the partners have no incentive to engage in such renegotiation.

${ }^{26}$ All proofs are in the Appendix.
} 
where

$$
r \equiv r_{0}+\lambda
$$

The resources contributed by firm $i$ at the start of separate operations are $e_{i, S}=k_{i}(0)\left(\gamma / \omega_{i}\right)^{1 / 1-\gamma}$.

Let $S_{i}(0) \equiv V_{i, S}\left(k_{i}(0)\right) / V_{j, S}\left(k_{j}(0)\right)$ denote the value at date 0 of firm $i$ 's separate operations relative to firm $j$ 's $(i \neq j)$. Using (10), we have

$$
S_{i}(0)=\frac{k_{i}(0)}{\omega_{i}^{\frac{\gamma}{1-\gamma}}} \frac{\omega_{j}^{\frac{\gamma}{1-\gamma}}}{k_{j}(0)}
$$

Without loss of generality, we assume that $S_{a}(0) \geq 1$ and refer to firm $a$ as the superior user of the asset at date $t=0$. The constancy of knowhow under separate operations then implies that the asset should be owned by firm $a$. Under separate operations, the optimal allocation of ownership is constant through time and depends only on the exogenous characteristics of the firms, $\left(k_{a}(0), \omega_{a}\right)$ and $\left(k_{b}(0), \omega_{b}\right)$.

Furthermore, to the extent that the original owner of the asset at date $t=0$ differs from the superior user of the asset at that date, the asset will immediately be traded. Thus, in case firm $b$ should own the asset at date $t=0$, it should sell the asset to firm $a$, for the latter firm is the superior user of the asset.

As noted in Section 1, we adopt the generalized Nash bargaining solution to determine the sale price of the asset, $p_{S}$. The Nash bargaining solution sets a price that distributes the gains from exchanging the asset in proportion to the partners' bargaining power. The payoffs in case of disagreement determine the upper and lower bound on that price. We solve for the Nash bargaining solution as follows: ${ }^{27}$ in the absence of an agreement to exchange the asset, the payoff to firm $a$ is zero, that to firm $b$ is $V_{b, S}\left(k_{b}(0)\right)$. The gain to buying the asset is $V_{a, S}\left(k_{a}(0)\right)-p_{S}$ for firm $a$. The gain to selling the asset is $p_{S}-V_{b, S}\left(k_{b}(0)\right)$ for firm $b$. The Nash bargaining solution is characterized as

$$
\max _{V_{b, S}\left(k_{b}(0)\right) \leq p_{S} \leq V_{a, S}\left(k_{a}(0)\right)}\left[V_{a, S}\left(k_{a}(0)\right)-p_{S}\right]^{\beta_{a}}\left[p_{S}-V_{b, S}\left(k_{b}(0)\right)\right]^{\beta_{b}} .
$$

It equals

$$
p_{S}=\beta_{b} V_{a, S}\left(k_{a}(0)\right)+\beta_{a} V_{b, S}\left(k_{b}(0)\right)
$$

\footnotetext{
${ }^{27}$ Our exposition of the solution follows Fan and Sundaresan (2000).
} 
The value of separate operations to firm $i, i \in\{a ; b\}$, at date $t=0$, including the value of the option to trade the asset, is then

$$
\begin{aligned}
& U_{a, S}(\mathbf{k}(0) \mid O) \equiv \begin{cases}V_{a, S}\left(k_{a}(0)\right) & \text { if } \quad O=b, \\
-p_{S}+V_{a, S}\left(k_{a}(0)\right) & \text { if } \quad O=b,\end{cases} \\
& U_{b, S}(\mathbf{k}(0) \mid O) \equiv\left\{\begin{array}{lll}
0 & \text { if } & O=a, \\
p_{S} & \text { if } & O=b .
\end{array}\right.
\end{aligned}
$$

where $O \in\{a ; b\}$ denotes the original owner of the asset. As the two firms internalize the option to trade the asset, the aggregate value of separate operations to the two firms at date $t=0$, including the option value of trading the asset, equals the value of separate operations to firm $a$, the superior user of the asset at date $t=0$

$$
W_{S}(\mathbf{k}(0)) \equiv U_{a, S}(\mathbf{k}(0) \mid \mathcal{O})+U_{b, S}(\mathbf{k}(0) \mid \mathcal{O})=V_{a, S}\left(k_{a}(0)\right)
$$

\section{Joint Operations without Moral Hazard}

We now consider the value of the joint venture, assuming it is the form of organization chosen at date $t=0$. We proceed by backward induction. We initially determine the value of the joint venture at dissolution, should such dissolution occur. We then determine the value of the joint venture before dissolution. For purposes of comparison, we first ignore any moral hazard consideration.

\subsection{The value of a dissolved joint venture}

Should the partners forego joint operations and the joint venture be dissolved, separate operations would nonetheless remain possible. ${ }^{28}$ If firm $i$ were to operate the asset separately after the joint venture is dissolved at a date $\hat{t}$, firm $i$ would have value at a date $t \geq \hat{t}$

$$
V_{i, S}\left(k_{i}(\hat{t})\right) \equiv \max _{\hat{e}_{i}}\left\{E_{t}\left[\int_{t}^{+\infty} \exp ^{-r_{0}(\tau-t)}\left[R\left(\hat{e}_{i}, k_{i}(\hat{t})\right)-C_{i}\left(\hat{e}_{i}\right)\right] 1_{\{\tau<\bar{t}\}} d \tau\right]\right\}
$$

Knowhow remains constant once the joint venture has been dissolved: $k_{i}(t)=k_{i}(\hat{t})$ for all $t \geq \hat{t}$. By analogy to the results of Proposition 1, we

\footnotetext{
${ }^{28}$ Note that a dissolution of the joint venture is necessarily permanent. This is because both knowhow and learning conditions remain unchanged during the phase of separate operations that follows dissolution.
} 
have $\hat{e}_{i}=k_{i}(\hat{t})\left(\gamma / \omega_{i}\right)^{1 / 1-\gamma}$ and

$$
V_{i, S}\left(k_{i}(\hat{t})\right)=\frac{k_{i}(\hat{t})}{r}(1-\gamma)\left(\frac{\gamma}{\omega_{i}}\right)^{\frac{\gamma}{1-\gamma}}
$$

Let $H \in\{a ; b\}$ refer to the partner that is the superior user of the asset at the date of dissolution, $\hat{t}$. Let $L \in\{a ; b\}$ refer to the other partner. That is, $S_{H}(\hat{t}) \geq 1$ and $S_{L}(\hat{t}) \leq 1$, where $S_{i}(\hat{t})$ is defined analogously to $S_{i}(0)$ in $(12)$, with $k_{i}(0)$ and $k_{j}(0)$ replaced by $k_{i}(\hat{t})$ and $k_{j}(\hat{t})$, respectively. Importantly, note that $H$ is not necessarily the superior user of the asset at date $t=0$, which we have assumed to be $a$. That is, the assumption $S_{a}(0) \geq 1$ does not imply $S_{a}(\hat{t}) \geq 1$.

\subsection{The first-best value of joint operations}

We begin with the assumption that each partner maximizes the value of the entire venture, rather than the value of the partner's own stake. The first-best value of joint operations at date $t \in[0 ; \hat{t}]$ is

$$
\begin{aligned}
W_{J}^{\prime}(x(t)) \equiv \max _{\left.\mathbf{e}\right|_{t=0}, \hat{t}}\left\{E_{t}\left[\int_{t}^{\hat{t}} \exp ^{-r_{0}(\tau-t)}\left[R_{J}(\mathbf{e})-C_{a}\left(e_{a}\right)-C_{b}\left(e_{b}\right)\right] 1_{(\tau<\bar{t})} d \tau\right]\right. \\
\left.+E_{t}\left[\exp ^{-r_{0}(\hat{t}-t)} V_{H, S}\left(k_{H}(\hat{t})\right) 1_{(\hat{t}<\bar{t})}\right]\right\} .
\end{aligned}
$$

The partners make the jointly optimal contributions to the venture $e_{i}{ }^{\prime} \equiv \arg \max _{e_{i}}\left[W_{J}^{\prime}(1)\right]$. They choose the jointly optimal dissolution time $\hat{t}^{\prime} \equiv \arg \max _{\hat{t}}\left[W_{J}^{\prime}(x(\hat{t}))\right]$. As the gain in knowhow, $g_{i}(t)$ in (6), is an increasing function of the state variable $x(t)$, the problem is weakly path dependent in the historical maximum of the geometric Brownian motion $y(t)$ over the period of joint operations. ${ }^{29}$ The optimization problem regarding the choice of dissolution time is then time homogeneous. Hence, $\hat{t}^{\prime}$ is the first time $x(t)$ reaches some upper timeindependent threshold level. That is, there exists a constant $\hat{x}_{J}^{\prime}$ such that $\hat{t}^{\prime}=\inf \left\{t \mid x(t)=\hat{x}_{J}^{\prime}\right\}$. Optimal dissolution then requires that partner $H$ operates the asset separately. We now show:

Proposition 2. The first-best value of joint operations to partner $i$, at a date $t \in\left[0 ; \hat{t}^{\prime}\right]$, is

\footnotetext{
${ }^{29}$ Equilibrium strategies are therefore Markov, open loop (i.e., state dependent) and perfect state (i.e., with perfect information).
} 


$$
\begin{array}{r}
W_{J}^{\prime}(x(t))=\frac{(1-\gamma)}{r} s\left(\mathbf{e}^{\prime}\right)^{\gamma} \bar{k}^{1-\gamma}\left[1-\left(\frac{x(t)}{\hat{x}_{J}^{\prime}}\right)^{\xi}\right] \\
+V_{H, S}\left(k_{H}\left(\hat{t}^{\prime}\right)\right)\left(\frac{x(t)}{\hat{x}_{J}^{\prime}}\right)^{\xi},
\end{array}
$$

where

$$
\begin{gathered}
s\left(\mathbf{e}^{\prime}\right)=\bar{k}\left(\frac{\gamma}{\omega_{a}^{\delta_{a}} \omega_{b}^{\delta_{b}}}\right)^{\frac{1}{1-\gamma}}, \\
\xi \equiv \sigma^{-2}\left[\sigma^{2} / 2-\mu+\sqrt{\left(\mu-\sigma^{2} / 2\right)^{2}+2 r \sigma^{2}}\right]
\end{gathered}
$$

and $r$ is given in (11). The resources contributed by partner $i$ are

$$
e_{i}^{\prime}=\frac{\delta_{i} \gamma}{\omega_{i}} s\left(\mathbf{e}^{\prime}\right)^{\gamma} \bar{k}^{1-\gamma}
$$

The knowhow attained by partner $i$ when dissolution occurs is

$$
k_{i}\left(\hat{t}^{\prime}\right)=\bar{k}\left(1-\frac{2 \xi}{1+\xi} \quad \frac{B(1)}{A_{H}(1)} \quad \frac{G_{i}(1)}{G_{H}(1)}\right)
$$

where

$$
\begin{gathered}
A_{i}(X) \equiv\left[1+\sqrt{1+\frac{2 f_{i}}{(1+\xi)^{2} G_{i}(X)}}\right], \\
B(X) \equiv 1-\left[\frac{\omega_{H}^{\delta_{L}} X}{\omega_{L}^{\delta_{L}}}\right]^{\frac{\gamma}{1-\gamma}},
\end{gathered}
$$

and

$$
G_{i}(X) \equiv\left(1-f_{i}\right) \frac{\bar{k}-k_{i}(0)}{2 \xi \bar{k} B(X)}
$$


Dissolution takes place the first time $x(t)$ reaches

$$
\hat{x}_{J}^{\prime}=(1+\xi) A_{H}(1) G_{H}(1)+f_{H}
$$

The superior user of the asset at dissolution, $H$, is always the low cost partner, that is $H$ is such that $\omega_{H}=\min \left\{\omega_{a} ; \omega_{b}\right\}$.

The term $\xi$ in (23) is the positive root of the characteristic equation $\xi^{2} \sigma^{2} / 2+\xi\left(\mu-\sigma^{2} / 2\right)-r=0$ and $\xi>1$. It is the elasticity of the probability of dissolution with respect to learning conditions, $x(t)$. The term $\left(x(t) / \hat{x}_{J}^{\prime}\right)^{\xi}$ in (21) is the probability-weighted discount factor for the gains from dissolution at date $\hat{t}^{\prime}$.

Equation (21) reflects the option value to dissolution. For $t<\hat{t}^{\prime}$, the value of the venture equals the sum of capitalized profits under joint operations and the value of the asset under separate operations, adjusted for the exercise of the option to dissolve that exchanges the former for the latter. At $t=\hat{t}^{\prime}$, joint operations are abandoned for separate operations by the superior user of the asset. As $\hat{x}_{J}^{\prime}$ is reached with certainty, the joint venture is dissolved with certainty.

To understand this result, recall that the acquisition of knowhow increases the partners' ability to operate the asset separately. It consequently decreases the benefits that combining and acquiring knowhow confer to joint operations relative to separate operations. Eventually, such benefits are no longer sufficient to offset the costs associated with the discrepancy in costs. ${ }^{30}$ Joint operations are then abandoned for separate operations.

The discrepancy in costs $\left(\omega_{a} \neq \omega_{b}\right)$ decreases the low-cost partner's contribution. ${ }^{31}$ It implies that the buying partner at the time of dissolution necessarily will be the low-cost partner, for the cost of the discrepancy would otherwise be compounded rather than alleviated. Consequently, in the absence of moral hazard, the joint venture will not be dissolved before the low-cost partner has become the superior user of the asset. An extended period of joint operations allows each partner to acquire most of its counterpart's knowhow. Each partner's knowhow then approaches the combined knowhow, $\bar{k}$. In the absence of a large difference in the partners' knowhow, the profitability of the separate operation of the asset following dissolution depends on the user's cost. This makes the low-cost partner the superior user of the asset.

\footnotetext{
${ }^{30}$ Note that there is no cost of moral hazard in the present case. This can be seen by comparing $e^{\prime}{ }_{a}+e^{\prime}{ }_{b}$ from (24) with $\hat{e}_{i}=k_{i}(\hat{t})\left(\gamma / \omega_{i}\right)^{1 / 1-\gamma}$ from Section 3.1. Absent differences in knowhow and in costs, the resource contributed are the same.

31 This can be seen from (24) and (22), which show the low-cost partner's contribution to be decreased by the high-cost partner's high cost.
} 


\section{Joint Operations with Moral Hazard}

We now consider the case where each partner pursues its own interest and maximizes the value of its own stake in the venture. We specify a contract that regulates the relations between the partners in Section 4.1. We derive an optimal contract and the corresponding value of joint operations in the presence of moral hazard in Section 4.2. We discuss how to implement the optimal contract in Section 4.3. In Section 4.4, we compute the contract payments made at the formation of the joint venture.

\subsection{The contract between the partners}

We assume that joint revenue, $R_{J}(\mathbf{e})$, is observable and verifiable, but that the resources contributed to the venture, e, are neither observable nor verifiable. Returning to the example of Section 1, it may be difficult to contract upon the skills and competencies of the engineers or scientists delegated to the venture and even precisely to ascertain such skills. We further assume that the state variable, $x(t)$, is observable but not verifiable. The partners in the joint venture are therefore limited to writing a contract that conditions each partner's payoff on the venture's revenues. We consider an equity-like contract. ${ }^{32}$ The contract promises each partner a constant share $\phi_{i}, 0<\phi_{i}<1$, of the joint revenues $R_{J}(\mathbf{e})$, with $\phi_{a}+\phi_{b}=1 .^{33}$

The contract also specifies the rules that govern exit from the venture. Recall from Section 1 that we seek a renegotiation proof equilibrium, to avoid the distortion to the partners' choices caused by the expectation of renegotiation. A necessary condition for the contract to be renegotiation proof is that it allocates the asset to the superior user at dissolution, $H$. We therefore consider exit rules whose payoffs to the partners are affine functions of the value of the asset in the hands of the superior user at dissolution, $H$. That is, denoting $V_{i}^{*}\left(k_{H}(\hat{t})\right)$ the payoff to partner $i$ at dissolution,

$$
V_{i}^{*}\left(k_{H}(\hat{t})\right)=\psi_{i}^{0}+\psi_{i}^{H} V_{H, S}\left(k_{H}(\hat{t})\right),
$$

where $\left(\psi_{i}^{0}, \psi_{i}^{H}\right) \in \mathbf{R}^{2}$ are such that $\psi_{a}^{0}+\psi_{b}^{0}=0$ and $\psi_{a}^{H}+\psi_{b}^{H}=1$.

\subsection{The optimal contract and the second-best value}

Renegotiation proofness requires that the partners' optimal dissolution times coincide, i.e., $\hat{t}_{a}=\hat{t}_{b}$, where $\hat{t}_{i}$ denotes partner's $i$ 's optimal

\footnotetext{
${ }^{32}$ The optimal contract we derive is therefore optimal only among equity-like contracts. We do not consider debt- or convertible-like contracts because these rarely are used in joint ventures.

${ }^{33}$ The inequalities are strict as each partner must be induced to make some non-zero contribution to the venture.
} 
dissolution time. ${ }^{34}$ The exit contract we derive in the present section is intended to achieve such coincidence. To the partners, the expectation of renegotiation proofness implies that the actual dissolution time, $\hat{t}$, is the earlier of the two partners' privately optimal dissolution times, $\hat{t}_{a}$ and $\hat{t}_{b}$. That is, $\hat{t} \equiv \min \left\{\hat{t}_{a} ; \hat{t}_{b}\right\}$. The equilibrium we seek is therefore a Nash Equilibrium in which i) the partners expect no renegotiation, ii) each partner chooses its privately optimal dissolution time, iii) the exit contract ensures that the partners' optimal dissolution times are identical, and iv) neither partner wishes to renegotiate.

We denote by $V_{i, J}(x(t))$ the value to partner $i$ of operating the asset jointly with partner $j$, at a date $t \geq 0$. Each partner $i$ maximizes $V_{i, J}(x(t))$ over the partner's resource contribution to the venture and the time at which to dissolve the venture. The partners' optimization problems are therefore

$$
\left\{\begin{array}{c}
V_{a, J}(x(t))=\max _{\left.e_{a}\right|_{t=0}, \hat{t}_{a}}\left\{E_{t}\left[\int_{t}^{\hat{t}} \exp ^{-r_{0}(\tau-t)}\left[\phi_{a} R_{J}(\mathbf{e})-C_{a}\left(e_{a}\right)\right] 1_{(\tau<\bar{t})} d \tau\right]\right. \\
\left.+E_{t}\left[\exp ^{-r_{0}(\hat{t}-t)} V_{a}^{*}\left(k_{H}(\hat{t})\right) 1_{(\hat{t}<\bar{t})}\right]\right\} \\
V_{b, J}(x(t))=\max _{\left.e_{b}\right|_{t=0}, \hat{t}_{b}}\left\{E_{t}\left[\int_{t}^{\hat{t}} \exp ^{-r_{0}(\tau-t)}\left[\phi_{b} R_{J}(\mathbf{e})-C_{b}\left(e_{b}\right)\right] 1_{(\tau<\bar{t})} d \tau\right]\right. \\
+E_{t}\left[\exp ^{-r_{0}(\hat{t}-t)} V_{b}^{*}\left(k_{H}(\hat{t})\right) 1_{(\hat{t}<\bar{t})]\} .}\right.
\end{array}\right.
$$

Both parties take into account that the actual dissolution time, $\hat{t}$, is the earlier of the two partners' privately optimal dissolution times, $\hat{t}_{a}$ and $\hat{t}_{b}$. Here again, each partner's optimization problem regarding the choice of dissolution time is time homogeneous. Hence, each partner's privately optimal time of dissolution, $\hat{t}_{i}$, is the first time $x(t)$ reaches some upper time-independent threshold level. That is, there exists a constant $\hat{x}_{i}$ such that $\hat{t}_{i}=\inf \left\{t \mid x(t)=\hat{x}_{i}\right\}$. We denote the aggregate value of joint operations to the two partners

$$
W_{J}(x(t)) \equiv V_{a, J}(x(t))+V_{b, J}(x(t)) .
$$

We derive the value of the joint venture for each partner and characterize each partner's optimal dissolution time and resource contribution. We then derive the optimal renegotiation proof contract. We present our results in two propositions, Proposition 3 and Proposition 4.

\footnotetext{
${ }^{34}$ The equality of the privately optimal dissolution times makes such time jointly optimal as well. There is therefore no possibility of increasing the parties' joint payoff by changing the time of dissolution.
} 
Proposition 3. A family of renegotiation-proof contracts that maximizes the value of the joint venture consists of (i) a sharing rule

$$
\phi_{i}=\left(\sqrt{1+N_{i}}-1\right) / N_{i},
$$

if $\delta_{a} \neq \delta_{b}$, and $\phi_{i}=1 / 2$ if $\delta_{a}=\delta_{b}$, where

$$
N_{i} \equiv \frac{\left(1-2 \delta_{i}\right)}{\delta_{i}\left(1-\gamma+\gamma \delta_{i}\right)},
$$

and (ii) an exit rule, $\left(\psi_{i}^{0}, \psi_{i}^{H}\right)$, satisfying

$$
\psi_{i}^{0}=M_{i} \frac{\bar{k}}{r}\left[\gamma\left(\frac{\phi_{a}}{\omega_{a}}\right)^{\delta_{a}}\left(\frac{\phi_{b}}{\omega_{b}}\right)^{\delta_{b}}\right]^{\frac{\gamma}{1-\gamma}},
$$

where

$$
M_{i} \equiv \psi_{i}^{H}\left(1-\phi_{i}\right) \gamma\left(2 \delta_{i}-1\right)+\left(\phi_{i}-\psi_{i}^{H}\right)\left(1-\gamma \delta_{i}\right) .
$$

In case the joint venture is dissolved, dissolution takes the form of the buyout of partner L by partner $H$.

The intuition for the results is as follows. Recall that $\delta_{i}$ indexes the relative importance of partner $i$ 's contribution to the venture. When $\delta_{i}>1 / 2$, partner $i$ 's contribution is more important, and $\phi_{i}>1 / 2$, reflecting the greater need to elicit that partner's contribution. ${ }^{35}$ Furthermore, when $\delta_{i}>1 / 2, \psi_{i}^{0}<0$ when $\psi_{i}^{H}=\phi_{i}$. Partner $j$, whose contribution is less important, should be more reluctant to dissolve the venture because joint operations allow that partner to profit from partner i's more important contribution. To be induced to choose dissolution at the same time as partner $i$, thereby ensuring renegotiation proofness, partner $j$ must be offered the payment $\psi_{j}^{0}=-\psi_{i}^{0}>0$ at dissolution. Alternatively, renegotiation proofness can be achieved by setting $\psi_{j}^{0}=0$ and $\psi_{j}^{H}>\phi_{j}$, thereby compensating partner $j$ by offering it a larger share of the value of the asset at dissolution than was its share of profits during joint operations.

Proposition 4. The value of joint operations to partner $i$, at a date $t \in[0 ; \hat{t}]$, is

\footnotetext{
${ }^{35}$ It is simple to show that $\partial \phi_{i} / \partial \delta_{i}>0$. Note that $\phi_{a}$ and $\phi_{b}$ are made renegotiation proof over the period of joint operations by their constancy over time.
} 


$$
\begin{aligned}
V_{i, J}(x(t))= & \frac{\phi_{i}\left(1-\gamma \delta_{i}\right)}{r} s(\mathbf{e})^{\gamma} \bar{k}^{1-\gamma}\left[1-\left(\frac{x(t)}{\hat{x}_{J}}\right)^{\xi}\right] \\
& +V_{i}^{*}\left(k_{H}(\hat{t})\right)\left(\frac{x(t)}{\hat{x}_{J}}\right)^{\xi}
\end{aligned}
$$

where $r$ and $\xi$ are given in (11) and (23), respectively, and where

$$
s(\mathbf{e})=\bar{k}\left[\gamma\left(\frac{\phi_{a}}{\omega_{a}}\right)^{\delta_{a}}\left(\frac{\phi_{b}}{\omega_{b}}\right)^{\delta_{b}}\right]^{\frac{1}{1-\gamma}} .
$$

The resources contributed by partner $i$ are

$$
e_{i}=\frac{\phi_{i} \delta_{i} \gamma}{\omega_{i}} s(\mathbf{e})^{\gamma} \bar{k}^{1-\gamma}
$$

The knowhow attained by partner $i$ when dissolution occurs is

$$
k_{i}(\hat{t})=\bar{k}\left(1-\frac{2 \xi}{1+\xi} \frac{B(\Delta)}{A_{H}(\Delta)} \frac{G_{i}(\Delta)}{G_{H}(\Delta)}\right),
$$

where $A_{i}(X), B(X)$, and $G_{i}(X)$ are given in (26), (27), and (28), respectively, and

$$
\Delta \equiv \phi_{a}^{\delta_{a}} \phi_{b}^{\delta_{b}}\left[\frac{1-\gamma\left(\phi_{a} \delta_{a}+\phi_{b} \delta_{b}\right)}{1-\gamma}\right]^{\frac{1-\gamma}{\gamma}}
$$

Dissolution takes place the first time $x(t)$ reaches

$$
\hat{x}_{J}=(1+\xi) A_{H}(\Delta) G_{H}(\Delta)+f_{H} .
$$

The superior user of the asset at dissolution, $H$, is partner $a$, if $\left.S_{a}(\hat{t})\right|_{H=a} \geq 1$, where

$$
\left.S_{a}(\hat{t})\right|_{H=a} \equiv \frac{\left.k_{a}(\hat{t})\right|_{H=a}}{\omega_{a}^{\frac{\gamma}{1-\gamma}}} \frac{\omega_{b}^{\frac{\gamma}{1-\gamma}}}{\left.k_{b}(\hat{t})\right|_{H=a}}
$$

is obtained using (40). Otherwise, the superior user, $H$, is partner $b$.

A comparison of (24) with (39) shows that moral hazard lowers the partners' resource contributions. 
Two results stand out. First, it is now possible for the high-cost partner to be the superior user of the asset at dissolution. Second, there are no learning races. We discuss these results in turn.

- The high-cost partner can be the superior user of the asset at dissolution:

Recall from the discussion that follows Proposition 2 that, in the absence of moral hazard, the joint venture will not be dissolved before the low-cost partner has become the superior user of the asset. When moral hazard is introduced, its cost may be so high as to warrant dissolution before such time. In such case, the high-cost partner will be the superior user of the asset, its high cost compensated by its still higher knowhow. Although buyout by the high-cost partner compounds the problem of the discrepancy in costs, it alleviates the problem of moral hazard.

Note that the presence of moral hazard is necessary but not sufficient for the high-cost partner to be the superior user of the asset at dissolution. Either partner can be the superior user at dissolution in the presence of moral hazard. For the high-cost partner to be the superior user, that partner's higher cost must be compensated by that same partner's higher knowhow. This is unlikely to be the case when the joint venture has been operating for a long time, for the low-cost partner then has acquired most of the knowhow of its high-cost counterpart. It is more likely to be the case when the joint venture is relatively short-lived, and the high-cost partner has greater ease of knowhow acquisition. ${ }^{36}$

- There are no learning races:

A learning race requires that a partner's payoff be increasing in that same partner's knowhow and decreasing in its counterpart's knowhow. Instead, (37) shows that both the partners' payoffs are increasing in the buying partner's knowhow at dissolution, $k_{H}(\hat{t})$, and that neither partner's payoff depends on the the selling partner's knowhow at dissolution, $k_{L}(\hat{t}) .{ }^{37}$ As noted in the Introduction, this result crucially depends on the presence of an exit contract that makes the terms of dissolution renegotiation proof, thereby denying the partners the incentive to acquire knowhow for the purpose of affecting negotiation.

\subsection{Implementing the second-best contract}

We now show how to implement the second-best contract derived in Proposition 3, particularly the optimal exit rule.

\footnotetext{
${ }^{36}$ The greater the high-cost partner's ease of knowhow acquisition, $f_{i}$, the higher that same partner's knowhow. Formally, partner $i$ 's knowhow at dissolution can be seen from (26) and (28) to increase in $f_{i}$.

${ }^{37}$ Interestingly, if it were possible for the partners to strategically manipulate the ease of knowhow acquisition, $f_{i}$, both partners would wish to increase $f_{H}$, and neither partner would be concerned with $f_{L}$.
} 
A mechanism commonly used in joint venture agreements is the "CakeCutting Mechanism" (CCM) ${ }^{38}$ The heart of the mechanism is as follows: The "Cake-Cutting Mechanism": At dissolution, partner $j \in\{a ; b\}$, chooses an exit price for the asset, $W^{C C M}$. Partner $i \in\{a ; b\}$, with $i \neq j$, either buys out partner $j$ for $\phi_{j} W^{C C M}$ or sells out to partner $j$ for $\phi_{i} W^{C C M}$. We show in the Appendix that the CCM amounts to an exit rule that has partner $H$ buy out partner $L$ at dissolution and sets

$$
\left(\psi_{i}^{0}, \psi_{i}^{H}\right),\left(\psi_{j}^{0}, \psi_{j}^{H}\right)= \begin{cases}\left(0, \phi_{i}\right),\left(0, \phi_{j}\right) & \text { if }(i, j)=(H, L), \\ \left(0, \phi_{i} \frac{V_{i, S}\left(k_{i}(\hat{t})\right)}{V_{j, S}\left(k_{j}(\hat{t})\right)}\right),\left(0,1-\phi_{i} \frac{V_{i, S}\left(k_{i}(\hat{t})\right)}{V_{j, S}\left(k_{j}(\hat{t})\right)}\right) & \text { if }(i, j)=(H, L) .\end{cases}
$$

The CCM effectively gives all bargaining power to partner $j$, as it grants that partner the privilege to make a take-it-or-leave-it offer when setting the exit price. ${ }^{39}$

The discussion in the Appendix and (44) show that the CCM corresponds to the optimal exit rule $\left[\left(\psi_{i}^{0}, \phi_{i}\right),\left(\psi_{j}^{0}, \phi_{j}\right)\right]$ only if $j=L$ and if supplemented by the payments $\psi_{i}^{0}$ and $\psi_{j}^{0}$. We have seen that Proposition 4 identifies the partner $H \in\{a ; b\}$ who should buy out its counterpart to operate the asset alone. It consequently identifies the partner $L$ who should set the exit price at dissolution for the optimal exit rule to be implemented.

Corollary 1. A renegotiation-proof contract that maximizes the value of the joint venture consists of (i) a sharing rule $\phi_{i}$ given in (33) and (ii) a CCM exit rule where the choice of the exit price is the prerogative of the inferior user of the asset at dissolution, partner L, combined with a payment

$$
\psi_{i}^{0}=\phi_{i}\left(1-\phi_{i}\right) \gamma\left(2 \delta_{i}-1\right) \frac{\bar{k}}{r}\left[\gamma\left(\frac{\phi_{a}}{\omega_{a}}\right)^{\delta_{a}}\left(\frac{\phi_{b}}{\omega_{b}}\right)^{\delta_{b}}\right]^{\frac{\gamma}{1-\gamma}} .
$$

Partner $L$ is identifiable as the partner for which $S_{L}(\hat{t})<1$, where $S_{L}(\hat{t})$ is obtained using the expressions for the partners' knowhow in (40).

\footnotetext{
${ }^{38}$ The CCM is also known as the "Russian Roulette" clause, the "Texas Shootout" clause, the "Dynamite" clause, or the "Shotgun" clause. See Crawford and Heller (1979) for a formal analysis of the CCM under symmetric information and Cramton, Gibbons, and Klemperer (1987), McAfee (1992), and Minehart and Neeman (1999) for an analysis of how to dissolve a partnership under asymmetric information. The latter two articles consider the role of the CCM in such circumstances.

${ }^{39}$ Note that the CCM provides the partner presented with the exit price, partner $i$, with the ability to "turn the table" on the partner that sets the exit price, partner $j$. This ensures that partner $j$ neither inflates the price if wishing to sell nor deflates it if wishing to buy.
} 


\subsection{Initial transfers}

Although there is no sale of the asset at date $t=0$ in the case of joint operations, the initial owner of the asset must be compensated for contributing the asset to the joint venture. The same is true for the firm that is expected to make the contribution of greater relative importance to the venture. As noted in Section 1, we adopt the generalized Nash bargaining solution to determine the payment made by one partner to the other at date $t=0$. Cash is paid in exchange for a stake in a joint venture with a partner that may be bringing the asset into the venture or may be making a contribution of greater relative importance to the venture. We denote $p_{J}$ the (possibly negative) payment from firm $a$ to firm $b$. We recall that $O \in\{a ; b\}$ denotes the original owner of the asset. We define $V_{i, S}\left(k_{i}(0) \mid O\right) \equiv V_{i, S}\left(k_{i}(0)\right)$ if $O=i$ and $V_{i, S}\left(k_{i}(0) \mid O\right) \equiv 0$ if $O \neq i$. In the absence of an agreement to form the venture, the payoff to firm $a$ is $V_{a, S}\left(k_{a}(0) \mid O\right)$, that to firm $b$ is $V_{b, S}\left(k_{b}(0) \mid O\right) .{ }^{40}$ The incremental value for firm $a$ of becoming a partner in the joint venture is $V_{a, J}(1)-p_{J}-V_{a, S}\left(k_{a}(0) \mid O\right)$. The incremental value for firm $b$ of becoming a partner in the joint venture is $V_{b, J}(1)+p_{J}-V_{b, S}\left(k_{b}(0) \mid O\right)$. By analogy to the analysis in Section 2, the Nash solution can be shown to be

$$
p_{J}=\beta_{b}\left[V_{a, J}(1)-V_{a, S}\left(k_{a}(0) \mid \mathcal{O}\right)\right]+\beta_{a}\left[V_{b, S}\left(k_{b}(0) \mid \mathcal{O}\right)-V_{b, J}(1)\right] .
$$

Given that $W_{J}(1)=V_{a, J}(1)+V_{b, J}(1)$, the value of joint operations to firm $i, i \in\{a ; b\}$, at date $t=0$, including the payment from firm $a$ to firm $b$, is then

$$
\begin{aligned}
& U_{a, J}(\mathbf{k}(0) \mid \mathcal{O}) \equiv \begin{cases}\beta_{a} W_{J}(1)+\left(1-\beta_{a}\right) V_{a, S}\left(k_{a}(0)\right) & \text { if } \mathcal{O}=a, \\
\beta_{a} W_{J}(1)-\beta_{a} V_{b, S}\left(k_{b}(0)\right) & \text { if } \mathcal{O}=b,\end{cases} \\
& U_{b, J}(\mathbf{k}(0) \mid \mathcal{O}) \equiv \begin{cases}\beta_{b} W_{J}(1)-\beta_{b} V_{a, S}\left(k_{a}(0)\right) & \text { if } \mathcal{O}=a, \\
\beta_{b} W_{J}(1)+\left(1-\beta_{b}\right) V_{b, S}\left(k_{b}(0)\right) & \text { if } \mathcal{O}=b .\end{cases}
\end{aligned}
$$

We clearly have

$$
U_{a, J}(\mathbf{k}(0) \mid \mathcal{O})+U_{b, J}(\mathbf{k}(0) \mid \mathcal{O})=W_{J}(1) .
$$

\section{Initial Organizational Form}

We now turn to the comparison of separate and joint operations for the purpose of determining the optimal organizational form at date $t=0$.

\footnotetext{
${ }^{40} \overline{\mathrm{We} \text { assume }}$ that the asset would be used by its original owner in case of disagreement.
} 
From the results in Section 2, we can write the value of the asset under separate operations at date $t=0$

$$
W_{S}(\mathbf{k}(0))=\frac{k_{a}(0)}{r}(1-\gamma)\left(\frac{\gamma}{\omega_{a}}\right)^{\frac{\gamma}{1-\gamma}}
$$

From the results in Section 4, we have the corresponding value under joint operations

$$
W_{J}(1)=\frac{\bar{k}}{r}(1-\gamma) \gamma^{\frac{\gamma}{1-\gamma}}\left(\frac{\Delta}{\omega_{a}^{\delta_{a}} \omega_{b}^{\delta_{b}}}\right)^{\frac{\gamma}{1-\gamma}}\left[1+\Gamma(\Delta) \hat{x}_{J}^{-\xi}\right]
$$

where

$$
\Gamma(X) \equiv\left[1-\frac{2 \xi}{1+\xi} \frac{B(X)}{A_{H}(X)}\right] \frac{1}{1-B(X)}-1,
$$

and

$$
\Delta=\phi_{a}^{\delta_{a}} \phi_{b}^{\delta_{b}}\left[\frac{1-\gamma\left[\phi_{a} \delta_{a}+\phi_{b} \delta_{b}\right]}{1-\gamma}\right]^{\frac{1-\gamma}{\gamma}}
$$

as in (41). Joint operations will be chosen in preference to separate operations at date $t=0$ when $W_{J}(1) \geq W_{S}(\mathbf{k}(0))$. Hence,

Corollary 2. Joint operations will be chosen over separate operations at date $t=0$ when

$$
k_{a}(0)\left(\frac{1}{\omega_{a}}\right)^{\frac{\gamma}{1-\gamma}} \leq \bar{k}\left(\frac{1}{\omega_{a}^{\delta_{a}} \omega_{b}^{\delta_{b}}}\right)^{\frac{\gamma}{1-\gamma}} \Delta^{\frac{\gamma}{1-\gamma}}\left[1+\Gamma(\Delta) \hat{x}_{J}^{-\xi}\right] .
$$

From inequality (54) we can see that

(i) An advantage of joint operations over separate operations is the combination of the partners' knowhow $\left(\bar{k}>k_{a}(0)\right)$.

(ii) A disadvantage of joint operations is the inability to have all resources contributed by the low-cost partner $\left(\omega_{a}^{\delta_{a}} \omega_{b}^{\delta_{b}}>\min \left\{\omega_{a} ; \omega_{b}\right\}\right)$

(iii) A disadvantage of joint operations is the moral hazard problem [ $\phi_{a}<1$ and $\phi_{b}<1$ in $\Delta$ can be shown to decrease $\Delta$ below 1]. 
(iv) Finally, an advantage of joint operations is the option value of dissolving the venture and abandoning joint operations for separate operations when the latter dominate. This advantage is reflected in the factor $\left[1+\Gamma(\Delta) \hat{x}_{J}^{-\xi}\right]$.

Interestingly, even if considerations (i) to (iii) were such that separate operation of the asset by firm $a$ dominates joint operations net of the option value of dissolution, consideration (iv) may nonetheless impart a preference for joint operations.

Note that there are no circumstances under which joint operations are preceded by a phase of separate operations. Such an occurrence would require inequality (54) to be false at the outset and become true after some period of separate operations. But neither side of the inequality will change during separate operations. This is because both knowhow and learning conditions remain unchanged under separate operations. Thus, should inequality (54) fail to hold at date $t=0$, and separate operations therefore be chosen at the outset, the inequality will fail to hold for all $t>0$.

Furthermore, regardless of whether joint or separate operations dominate, there are no circumstances under which the dominant form of operations should be delayed. This is because not operating is never worthwhile, as the values $V_{i, S}\left(k_{i}(0)\right)$ and $V_{i, J}(x(t))$ in (10) and (37), respectively, are always positive. ${ }^{41}$

\section{The Duration of the Joint Venture}

The duration of the joint venture is the time elapsed between the date $t=0$ at which the joint venture is formed and the date $t=\hat{t}$ at which it is dissolved. The latter is the time at which learning conditions reach the state $\hat{x}_{J}$. We establish the following comparative statics results, distinguishing somewhat arbitrarily between the characteristics of the venture and those of the partners.

Lemma 1. The duration of a joint venture is

(i) decreasing in the discount rate, $r_{0}$,

(ii) decreasing in the intensity of failure, $\lambda$,

(iii) decreasing in the underlying trend of learning conditions, $\mu$,

(iv) increasing in the underlying volatility of learning conditions, $\sigma$.

\footnotetext{
${ }^{41}$ The constancy of $y(t)$ under separate operations implies that there is no option value to waiting for an improvement in learning conditions. See McDonald and Siegel (1986) for an analysis of the value of the option of waiting to invest.
} 
The results are quite intuitive. Result (i) reflects the fact that a joint venture can be viewed as an investment in transferring knowhow. The higher the discount rate, the less valuable the future benefits to such transfer, and the smaller the investment. A smaller investment takes the form of a shorter lived joint venture. Result (ii) is similar to result (i). Liquidation renders worthless the investment made in transferring knowhow. The higher the intensity of failure, the higher the probability of liquidation and the smaller the investment. Result (iii) reflects the faster rise of learning conditions to the state $\hat{x}_{J}$ that comes from a larger trend. Finally, result (iv) reflects the fact that higher volatility makes the option to dissolve more valuable. The partners are therefore less likely to 'kill' the option by dissolving the venture.

Lemma 2. The duration of a joint venture is

(i) increasing in the overall knowhow of the partners, $\bar{k}$,

(ii) decreasing in the initial knowhow of the buying partner, $k_{H}(0)$,

(iii) unaffected by the initial knowhow of the selling partner, $k_{L}(0)$,

(iv) decreasing in the ease with which partner $H$ acquires knowhow, $f_{H}$,

(v) unaffected by the ease with which partner L acquires knowhow, $f_{L}$,

(vi) increasing in the cost of the buying partner, $\omega_{H}$,

(vii) decreasing in the cost of the selling partner, $\omega_{L}$.

Again, the results are quite intuitive. Results (i) and (ii) reflect the fact that the more knowhow there is for the buying partner to acquire, the longer that partner will wish to remain in the venture. Result (iii) reflects the fact that the initial knowhow of the selling partner has no effect on the knowhow of the buying partner. Only the latter knowhow matters to the decision to dissolve the joint venture. Results (iv) and (v) are the counterparts to results (ii) and (iii), applied to the partners' ease of knowhow acquisition. The faster the buying partner acquires knowhow, the shorter the duration of the joint venture. How fast the buying partner acquires knowhow depends on that partner's ease of knowhow acquisition but not on that of its partner. Results (vi) and (vii) reflect the cost of the discrepancy in costs. The higher the cost of the buying partner, the longer that partner wishes to share the cost of contributing resources with its counterpart. The higher the cost of the selling partner, the sooner the buying partner wishes to buy it out.

Upon forming the joint venture, the partners will wish to form an expectation of the duration of the joint venture and to obtain some measure of uncertainty of that duration. At the date $t=0$, the joint venture has expected duration $E_{0}[\hat{t}]$ and variance $V_{0}[\hat{t}]$ given by ${ }^{42}$

\footnotetext{
${ }^{42}$ See Cox and Miller (1984, p. 221) for the moments of the first passage time to an upper absorbing barrier of an upward drifting geometric Brownian motion.
} 


$$
E_{0}[\hat{t}]=\frac{\ln \left(\hat{x}_{J}\right)}{\mu-\sigma^{2} / 2} \text { and } V_{0}[\hat{t}]=\frac{\sigma^{2} \ln \left(\hat{x}_{J}\right)}{2\left(\mu-\sigma^{2} / 2\right)^{3}}, \quad \text { if } \mu>\sigma^{2} / 2,
$$

and $E_{0}[\hat{t}] \rightarrow+\infty$ and $V_{0}[\hat{t}] \rightarrow \infty$ if $\mu \leq \sigma^{2} / 2$. $^{43}$ Denoting by $f_{0}(t)$ the probability density function of the time to dissolution and by $E D F(t)$ the expected dissolution frequency of the venture, we have ${ }^{44}$

$$
f_{0}(t)=\frac{\ln \left(\hat{x}_{J}\right)}{\sigma \sqrt{2 \pi t^{3}}} \exp \left[-\left[\frac{\ln \left(\hat{x}_{J}\right)-\left(\mu-\sigma^{2} / 2\right) t}{2 \sigma^{2} t}\right]^{2}\right]
$$

and

$$
\begin{aligned}
E D F(t)= & N\left[\frac{-\ln \left(\hat{x}_{J}\right)+\left(\mu-\sigma^{2} / 2\right) t}{\sigma \sqrt{t}}\right] \\
& +\exp \left[\frac{2 \ln \left(\hat{x}_{J}\right)\left(\mu-\sigma^{2} / 2\right)}{\sigma^{2}}\right] N\left[\frac{-\ln \left(\hat{x}_{J}\right)-\left(\mu-\sigma^{2} / 2\right) t}{\sigma \sqrt{t}}\right],
\end{aligned}
$$

where $N($.$) denotes the cumulative normal distribution.$

\section{Example}

We illustrate selected results by way of a numerical example. We choose a set of parameter values that generate duration $E_{0}[\hat{t}]=7.25$ years and expected dissolution frequency at year $10 \operatorname{EDF}(10)=81.6 \%$, in line with what appears to be the case for joint ventures. ${ }^{45}$ Figure 6 plots (a) the probability density function of the time to dissolution, $\hat{t}$, and (b) its expected dissolution frequency.

The parameter values correspond to a situation in which partner $a$ has both lower cost and lower initial knowhow than its counterpart $b$ $\left(\omega_{a}=10, \omega_{b}=25, k_{a}(0)=40\right.$, and $\left.k_{b}(0)=60\right)$. There is no overlap in initial knowhow $\left(\bar{\kappa}=k_{a}(0)+k_{b}(0)=100\right)$, so that a partner's potential gain in knowhow is the entirety of its partner's knowhow. The partners are otherwise identical, both in terms of the contributions they make to the venture $\left(\delta_{a}=\delta_{b}=1 / 2\right)$ and in terms of their ease of knowhow

\footnotetext{
${ }^{43}$ Note that, when $\mu \leq \sigma^{2} / 2$, the probability of reaching the (finite) state $\hat{x}_{J}$ equals one despite the expectation and variance of the random time at which that state is reached being infinite (Cox and Miller, 1984, p. 221).

${ }^{44}$ The expected dissolution frequency at date $t$ is the probability that dissolution occurs at or before that date. It can be viewed as the counterpart in joint ventures to the expected default frequency analyzed by Huang and Huang (2002) and Leland (2004) in their assessment of structural asset pricing models of the firm.

45 These values are close to those that are either reported in or can be inferred from Kogut (1991).
} 
(a)

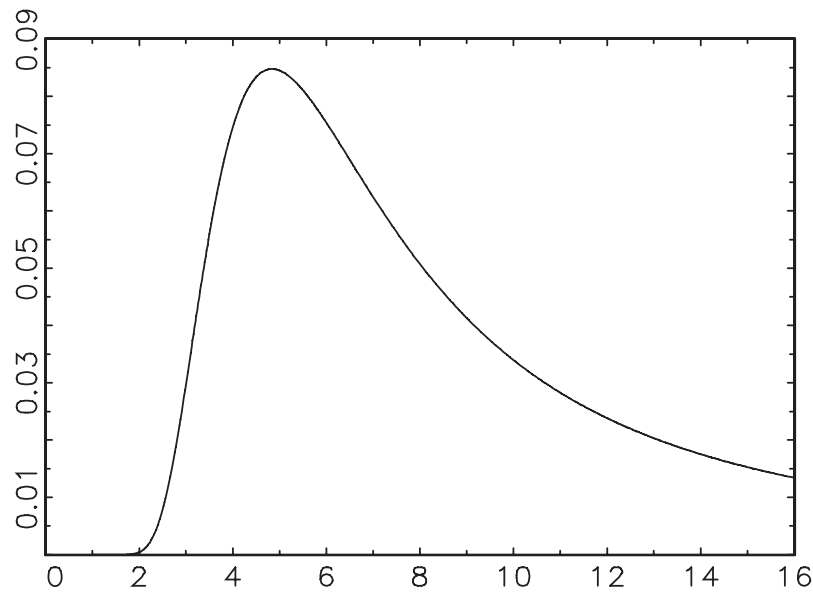

(b)

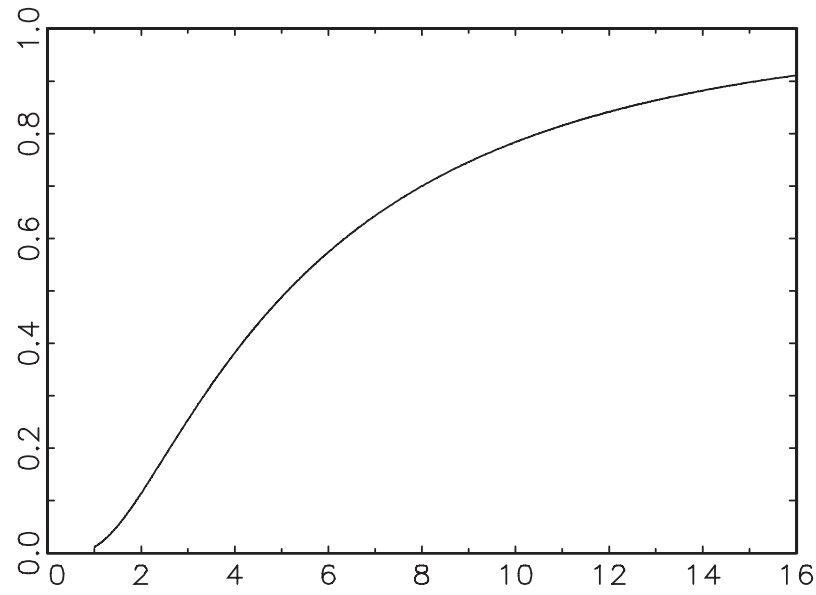

Figure 6

Uncertainty in Joint Venture Duration, in the Baseline Case

(a) Probability density function of joint venture duration, $f_{0}(t)$. (b) Expected dissolution frequency, $E D F(t)$ (probability that dissolution occurs before date $t$ ). The horizontal axis shows time $t$ in years.

acquisition $\left(f_{a}=f_{b}=0.4\right)$. Resource contributions and knowhow are equally important $(\gamma=0.5)$. Finally, $r_{0}=8 \%, \lambda=1 \%, \mu=0.1$, and $\sigma=0.1$.

With the preceding parameter values, joint operations are preferred to separate operations but only because of the option value of dissolution. ${ }^{46}$

\footnotetext{
${ }^{46}$ Inequality (54) in Corollary 2 holds, but it would not hold were we to impose the condition $\Gamma(\Delta) \hat{x}_{J}^{-\xi}=0$.
} 
The optimal contract consists of (i) an equal sharing rule $\left(\phi_{a}=\phi_{b}=1 / 2\right)$ and (ii) a CCM exit rule with no transfer payment $\left(\psi_{a}^{0}=\psi_{b}^{0}=0\right)$. The buying partner, $H$, is partner $a$. Interestingly, when the venture is dissolved, partner $a$ has acquired only $g_{a}(\hat{t}) /\left[\bar{k}-k_{a}(0)\right]=56.73 \%$ of the knowhow it can potentially acquire from partner $b$. Partner $a$ chooses to forego the remaining knowhow to avoid having to bear the costs of joint operations, in the present case the cost of moral hazard and that of working with a higher cost partner $\left(\omega_{a}=10<25=\omega_{b}\right)$.

\section{Moral Hazard}

We conduct a detailed comparison of the results of Propositions 2 and 4 . We have already mentioned the lower resources contributed by the partners and the possibility for the high-cost partner to be the superior user of the asset at dissolution in the discussion that followed Proposition 4.

Another effect of moral hazard is to decrease the duration of the joint venture. ${ }^{47}$ This can be seen by noting that (29) is identical to (42), with 1 in the former replaced by $\Delta$ in the latter. As $\Delta \leq 1$ and the product $A_{H}(\Delta) G_{H}(\Delta)$ increases in $\Delta$, we have $\hat{x}_{J} \leq \hat{x}_{J}^{\prime}{ }^{48}$ The intuition of this result is that decreased contributions by the partners diminish the profitability and thus the duration of joint operations.

An immediate effect of the shorter duration of the joint venture in the presence of moral hazard is the lower knowhow of the buying partner, $H$, at dissolution. This can be shown formally by noting that the ratio $B(\Delta) / A_{H}(\Delta)$ in (25) and (40) decreases in $\Delta$. A related effect is the lower value of the joint venture at date $t=0$. As noted in Corollary 2, that value in the presence of moral hazard is the RHS of (54). In the absence of moral hazard, the value of the joint venture is identical to the RHS of (54), with $\hat{x}_{J}$ replaced by $\hat{x}_{J}^{\prime}$ and $\Delta$ by 1 . The desired result is an immediate implication of the observation that $\Delta^{\gamma / 1-\gamma}\left[1+\Gamma(\Delta) \hat{x}_{J}^{-\xi}\right]$ increases in $\Delta .^{49}$

Finally, as the LHS of (54) is the same regardless of the existence of moral hazard, but the RHS is lower in the presence of moral hazard, we conclude that moral hazard makes joint operations less likely to be chosen in the first place.

We summarize the preceding results in Corollary 3.

\footnotetext{
${ }^{47}$ Double moral hazard thus plays in joint ventures a role similar to that played by coordination costs in mergers.

${ }^{48}$ That $\Delta \leq 1$ is shown in the Proof of Proposition 4.

${ }^{49}$ We use the Envelope Theorem to ignore the effect of the change from $\hat{x}_{J}$ to $\hat{x}_{J}^{\prime}$ on the RHS of (54).
} 
Corollary 3. Moral hazard (i) makes joint operations less likely to be chosen over separate operations at the outset, (ii) decreases the value of the joint venture when joint operations are chosen, (iii) decreases the resource contributions to the venture, (iv) shortens the duration of the joint venture, (v) lowers the knowhow attained by the buying partner at dissolution, and (vi) introduces the possibility for the high-cost partner to be the superior user of the asset at dissolution.

The effects of moral hazard are substantial. Continuing with the example presented in Section 7, the expected duration of the joint venture would be $\left(E_{0}\left[\hat{t}^{\prime}\right]-E_{0}[\hat{t}]\right) / E_{0}[\hat{t}]=27.3 \%$ longer in the absence of moral hazard. The expected dissolution frequency at year 10 would be $\left[E D F^{\prime}(10)-E D F(10)\right] / E D F(10)=-16.67 \%$ lower. Finally, the knowhow gained by partner $a$ at dissolution would be $\left[g_{a}\left(\hat{t}^{\prime}\right)-g_{a}(\hat{t})\right] / g_{a}(\hat{t})=13.77 \%$ larger.

\section{Testable Implications and Empirical Evidence}

We now briefly consider some testable implications of our results. Perhaps the most important implication is the prediction regarding the identity of the buying partner at dissolution. We predict this to be the low-cost partner for joint ventures that were in existence long enough for the low-cost partner to have acquired most of its partner's knowhow. It may be the high-cost partner when the venture is relatively short-lived, and the high-cost partner's ease of knowhow acquisition is greater than that of its counterpart. This prediction naturally begs the question of what exactly defines the 'cost' of a partner and what distinguishes such cost from the partner's knowhow and from the asset in the venture. We suggest that knowhow is what can be learned in the course of joint operations, the asset is what can be bought by one partner from the other, and cost is what can neither be learned nor be bought, at least at reasonable cost, within reasonable time, and with no marked decline in value as it is acquired. ${ }^{50}$ This definition in many ways recalls that of corporate advantage, often associated with "core competencies." ${ }^{51} \mathrm{We}$ would therefore predict that in joint ventures in which one partner considers the venture's business part of its core operations whereas the other does not, the former partner is the likely acquiror at dissolution. The joint

\footnotetext{
${ }^{50}$ How long is 'reasonable time' of course depends on the knowhow to be acquired. A long-lived venture may therefore be considered one that lasts longer than that period.

${ }^{51}$ For a discussion of corporate advantage, see for example Collis and Montgomery (1998). For a discussion of core competencies, see Prahalad and Hamel (1990).
} 
venture between BMW and Rolls-Royce mentioned in the Introduction appears to conform to that view, as do the large number of joint ventures that are essentially devices through which one partner exits a business no longer considered central to its operations. Numerous examples of such ventures are reported in Nanda and Williamson (1995) and include Whirlpool and Phillips in white goods, Corning Glass and Ciba-Geigy in medical diagnostics, and Dresser and Komatsu in construction equipment.

Another testable implication of our result is that learning races may not be as widespread as commonly believed. This is because exit contracts constrain bargaining, thereby limiting the scope for the partners to exploit any increased bargaining power they may derive from learning. Although the optimal contract we have derived is somewhat unusual in that it involves a transfer payment from one partner to the other over and above the price paid for the selling partner's share of the venture, it reduces to a relatively common version of the CCM when the partners' contributions are identical. ${ }^{52}$

A set of testable implications relates to the duration of the joint venture. There appears to exist little empirical evidence, supportive or otherwise, regarding most predictions, but approximate forms of two predictions have been tested. The first prediction is the longer duration of joint ventures in which more knowhow potentially can be acquired by the buying partner $(\partial \hat{t} / \partial \bar{k}>0)$. The second is the shorter duration of joint ventures in which the buying partner has greater ease of acquiring knowhow $\left(\partial \hat{t} / \partial f_{H}<0\right)$. Reuer, Zollo, and Singh (2002) study the likelihood of reorganization or buyout of equity and non-equity alliances in the biotechnology industry. ${ }^{53}$ They find this likelihood to be lower the greater the alliance's division of labor, that is, the greater the extent to which the partners perform different tasks within the alliance. The greater the alliance's division of labor, the greater, presumably, the discrepancy in the partners' initial knowhow regarding the different tasks, and the more knowhow potentially can be acquired. Park and Russo (1996) find that integrative joint ventures, that is, joint ventures that have their manufacturing facilities jointly built and operated by the partners, have shorter duration to buyout. Partners working side by side in a manufacturing facility presumably can learn more easily from each other, in contrast to partners working in separate facilities (what Park and Russo call sequential joint ventures, which they find have longer duration).

\footnotetext{
${ }^{52}$ Recall that $\psi_{a}^{0}=\psi_{b}^{0}=0$ when $\delta_{a}=\delta_{b}=1 / 2$.

${ }^{53} \mathrm{~A}$ joint venture is an equity alliance.
} 


\section{Conclusion}

We summarize the main findings of our analysis and discuss its limitations.

We believe our analysis has four main findings: that the acquisition of knowhow makes every joint venture temporary; that the partner that is bought out at dissolution need not be viewed as the losing party; that learning races may not be as widespread as commonly believed; and, most importantly perhaps, that it is possible to form an expectation of the duration of the joint venture at the outset and to identify the buying partner.

Our first finding, that the acquisition of knowhow makes every joint venture temporary, reflects the effects of knowhow acquisition on the balance of benefits and costs in the joint venture. The more knowhow has been acquired, the fewer the benefits of joint operations relative to separate operations. Because the costs of joint operations are unaffected, there comes a time at which the joint venture is dissolved.

An alternative interpretation is that the joint venture is an arrangement for transferring knowhow from one partner to the other to capitalize on the latter partner's lower cost or greater ease of knowhow acquisition. The joint venture is dissolved once the desired transfer of knowhow has taken place. Dissolution takes the form of the buyout of the inferior partner by its superior counterpart.

Our second finding is that the partner that is bought out at dissolution need not be viewed as the losing party. Despite being made the inferior partner by the process of transferring knowhow, the partner that is bought out is willing to take part in this process, because it shares in the ensuing increase in value through the buyout price it receives for its stake in the venture.

Our third finding is that there exists a contract that succeeds in making exit renegotiation proof and thereby precludes learning races. In view of the extensive discussion regarding learning races, this is a somewhat unexpected and relatively important result. The contract we derive resembles the cake-cutting mechanism commonly found in joint venture agreements and effectively reduces to a version of it in the case where the partners' contributions to the joint venture are identical and the partners hold equal shares of the venture. This finding suggests that the purpose of the various exit clauses found in joint venture contracts may be to constrain bargaining over exit conditions, thereby denying the parties the incentive to acquire knowhow for the sole purpose of affecting negotiation, that is, to engage in learning races.

Finally, our fourth finding is that it is possible to form an expectation of the duration of the joint venture at the outset and to identify the buying partner. The buying partner is the superior partner at dissolution but need 
not have been the superior user at date $t=0$. The buying partner is made superior user by its lower cost, its higher knowhow at the time of dissolution, or both. Duration and identity are related. The buying partner is necessarily the low-cost partner in a joint venture that is long-lived, for a long-lived venture provides each partner with the opportunity to acquire most of its counterpart's knowhow. In contrast, when moral hazard and the discrepancy in costs make the joint venture short lived, the buying partner may be the high-cost partner. The high-cost partner may be the superior user despite its higher cost, if that higher cost is offset by still higher knowhow, attained by virtue of the high-cost partner's greater ease of knowhow acquisition.

Turning to the limitations of our analysis, we believe that there are two main limitations. The first limitation is in the indispensable nature of the asset: no revenues can be produced without the asset. This implies that the superior user at dissolution cannot simply walk away from the venture and engage in separate operations using an alternative asset. To engage in separate operations, the superior user must buy out its inferior counterpart. This ensures that the latter partner shares in the gains made possible by the former partner's increased knowhow. Absent the need for the superior user to buy out its inferior counterpart, it may be possible for the superior user to avoid sharing the gains from increased knowhow. In such case, the inferior partner may no longer be willing to enter into the joint venture or, should it do so, it is unlikely to contribute its knowhow to the venture to the same extent.

The second limitation is in the limited operations of the two partners: the partners' only operations are those combined in the joint venture. Such a situation is not very common in practice, where most firms engaged in a joint venture likely have extensive fully-owned operations besides. To the extent that externalities exist between fully- and jointly-owned operations, the ability of the inferior partner to share in the gains from increased knowhow may be much diminished and thus its willingness to enter into and contribute to the joint venture. An offsetting effect, however, is that the inferior partner's fully-owned operations may profit from the knowhow that same partner acquires from the superior partner. Clearly, the resulting interactions are markedly more complex than those in this article. An analysis that addresses both limitations is important but best left for further work.

\section{Appendix}

Proof of Proposition 1. As in Lando (1994), discounting when liquidation occurs with intensity $\lambda$ is analogous to discounting at the sum of the short rate and that same intensity. Formally, we use

$$
E_{t}\left[1_{(\tau<t)}\right]=\exp ^{-\lambda(\tau-t)},
$$


to obtain

$$
\begin{gathered}
V_{i, S}\left(k_{i}(0)\right)=\max _{e_{i}}\left\{E_{t}\left[\int_{t}^{+\infty} \exp ^{-\left(r_{0}+\lambda\right)(\tau-t)}\left[R\left(e_{i}, k_{i}(0)\right)-C_{i}\left(e_{i}\right)\right] d \tau\right]\right\}, \\
=\left[R\left(e_{i}, k_{i}(0)\right)-C_{i}\left(e_{i}\right)\right] \frac{1}{r_{0}+\lambda} .
\end{gathered}
$$

Maximizing, we obtain $e_{i, S}=k_{i}(0)\left(\gamma / \omega_{i}\right)^{1 / 1-\gamma}$. Substituting, we have

$$
V_{i, S}\left(k_{i}(0)\right)=\frac{k_{i}(0)}{r_{0}+\lambda}\left(\frac{\gamma^{\frac{\gamma}{1-\gamma}}-\gamma^{\frac{1}{1-\gamma}}}{\omega_{i}^{\frac{\gamma}{1-\gamma}}}\right) .
$$

Simplifying and defining $r \equiv r_{0}+\lambda$ gives (10).

Proof of Proposition 2. To simplify the notation in this proof, we shall refrain from using primes to denote the first-best case. By analogy to the derivation in the Proof of Proposition 1 , we have

$$
\begin{aligned}
W_{J}(x(t)) \equiv & \max _{\left.\mathbf{e}\right|_{t=0}}\left\{E_{t}\left[\int_{t}^{\hat{t}} \exp ^{-r(\tau-t)}\left[R_{J}(\mathbf{e})-C_{a}\left(e_{a}\right)-C_{b}\left(e_{b}\right)\right] d \tau\right]\right. \\
& \left.+E_{t}\left[\exp ^{-r(\hat{t}-t)} V_{H, S}\left(k_{H}(\hat{t})\right)\right]\right\} .
\end{aligned}
$$

Let $f_{t}\left(t\left(x^{*}\right)\right)$ denote the density of $t\left(x^{*}\right) \equiv \inf \left\{t \mid x(t)=x^{*}\right\}$ conditional on the information known at date $t$. The Laplace transform of $f_{t}\left(t\left(x^{*}\right)\right)$ is the probability weighted discount factor for the value of $\$ 1$ received at $t\left(x^{*}\right)$

$$
\int_{t}^{\infty} \exp ^{-r\left(t\left(x^{*}\right)-t\right)} f_{t}\left(t\left(x^{*}\right)\right) d t\left(x^{*}\right)=\left(\frac{x(t)}{x^{*}}\right)^{\xi}
$$

where

$$
\xi \equiv \sigma^{-2}\left[\sigma^{2} / 2-\mu+\sqrt{\left(\mu-\sigma^{2} / 2\right)^{2}+2 r \sigma^{2}}\right]
$$

Note that $\xi>1$. Using (63) we can write

$$
W_{J}(x(t))=\max _{\left.\mathbf{e}\right|_{t=0}, \hat{x}}\left\{\left[R_{J}(\mathbf{e})-C_{a}\left(e_{a}\right)-C_{b}\left(e_{b}\right)\right] / r\left\{1-\left[\frac{x(t)}{\hat{x}}\right]^{\xi}\right\}+V_{H, S}\left(k_{H}(\hat{t})\right)\left[\frac{x(t)}{\hat{x}}\right]^{\xi}\right\} .
$$

Proceeding backwards in time, we first characterize the partners' jointly optimal dissolution time.

Given that $k_{H}(\hat{t})=\bar{k}-\left[\bar{k}-k_{H}(0)\right]\left(1-f_{H}\right) /\left(\hat{x}-f_{H}\right)$, we have $\partial\left[k_{\hat{H}}(\hat{t})\right] / \partial_{\hat{x}}=$ $\left[\bar{k}-k_{H}(\hat{t})\right] /\left(\hat{x}-f_{H}\right)$. 
Differentiating (65) w.r.t. $\hat{x}$, we have

$$
\begin{aligned}
\frac{\partial W_{J}(x(t))}{\partial \hat{x}}= & \frac{1}{\hat{x}\left(\hat{x}_{i}-f_{H}\right)}\left[\frac{x(t)}{\hat{x}}\right]^{\xi}\left\{\xi\left(\hat{x}-f_{H}\right) \frac{\left[R_{J}(\mathbf{e})-C_{a}\left(e_{a}\right)-C_{b}\left(e_{b}\right)\right]}{r}\right. \\
& \left.-\left[\hat{x}+\xi\left(\hat{x}-f_{H}\right)\right] V_{H, S}\left(k_{H}(\hat{t})\right)+\hat{x} V_{H, S}(\bar{k})\right\} .
\end{aligned}
$$

Given that $V_{H, S}\left(k_{H}(\hat{t})\right)<V_{H, S}(\bar{k})$, the f.o.c. for $\hat{x}$ yields

$$
F(\hat{x})=\left(\frac{1-f_{H}}{\xi}\right) \frac{V_{H, S}\left(\bar{k}-k_{H}(0)\right)}{\left\{V_{H, S}(\bar{k})-\left[R_{J}(\mathbf{e})-C_{a}\left(e_{a}\right)-C_{b}\left(e_{b}\right)\right] / r\right\}},
$$

where

$$
F(\hat{x}) \equiv \frac{\left(\hat{x}-f_{H}\right)^{2}}{(1+\xi) \hat{x}-\xi f_{H}}
$$

if $\frac{\left[R_{J}(\mathbf{e})-C_{a}\left(e_{a}\right)-C_{b}\left(e_{b}\right)\right]}{r}<V_{H, S}(\bar{k})$ and $\hat{x} \rightarrow+\infty$ otherwise.

We then determine the partners' resource contributions. Using the Envelope Theorem, we have $d W_{J}(x(t)) / d e_{i}=\partial\left[R_{J}(\mathbf{e})-C_{a}\left(e_{a}\right)-C_{b}\left(e_{b}\right)\right] / \partial e_{i}\left[1-[x(t) / \hat{x}]^{\xi}\right]$, and the f.o.c. for $e_{i}$ directly yields (24). With (24) for partner $a$ and partner $b$, we obtain (22). With (24) we also obtain

$$
R_{J}(\mathbf{e})-C_{a}\left(e_{a}\right)-C_{b}\left(e_{b}\right)=(1-\gamma) s(\mathbf{e})^{\gamma} \bar{k}^{1-\gamma} .
$$

With (69) and (65), we obtain (21). Also, using (69) and (67), we have that $\hat{x}$ can be written as in (29), with $A_{H}(X)$ defined in (26). Using $k_{i}(\hat{t})=\bar{k}-\left[\bar{k}-k_{H}(0)\right]\left(1-f_{i}\right) /\left(\hat{x}-f_{H}\right)$ and (29), we obtain $k_{i}(\hat{t})$ given in (25). The identity of $H$ then follows.

We now show by contradiction that $\hat{x}$ is always finite: Assume that $\hat{x} \rightarrow+\infty$. Then $\left.k_{i}(t)\right|_{t \rightarrow+\infty}=\bar{k}$. It follows that $\left.S_{i}(t)\right|_{t \rightarrow+\infty}=\left(\omega_{j} / \omega_{i}\right)^{\gamma / 1-\gamma}$. Hence, the superior user of the asset at dissolution, $H$, is such that $\omega_{H}=\min \left\{\omega_{a} ; \omega_{b}\right\}$ in case of very late dissolution. Now, with (69), $\left[R_{J}(\mathbf{e})-C_{a}\left(e_{a}\right)-C_{b}\left(e_{b}\right)\right] / r<V_{H, S}(\bar{k})$ when

$$
\frac{\omega_{H}}{\omega_{L}}<1
$$

But if $\omega_{H}=\min \left\{\omega_{a} ; \omega_{b}\right\}$, then (70) holds. Hence, $\left[R_{J}(\mathbf{e})-C_{a}\left(e_{a}\right)-C_{b}\left(e_{b}\right)\right] / r<V_{H, S}(\bar{k})$ and so $\hat{x}$ is finite, which is a contradiction. Therefore, $\hat{x}$ is always finite.

We now show by contradiction that $H$ is such that $\omega_{H}=\min \left\{\omega_{a} ; \omega_{b}\right\}$ : Assume that $H$ is such that $\omega_{H}=\max \left\{\omega_{a} ; \omega_{b}\right\} . \quad$ Then $\left[R_{J}(\mathbf{e})-C_{a}\left(e_{a}\right)-C_{b}\left(e_{b}\right)\right] / r=$ $\bar{k} / r(1-\gamma)\left(\gamma / \omega_{a}^{\delta_{a}} \omega_{b}^{\delta_{b}}\right)^{\gamma / 1-\gamma}, \quad$ whereas $\quad V_{H, S}(\bar{k})=\bar{k} / r(1-\gamma)\left(\gamma / \max \left\{\omega_{a} ; \omega_{b}\right\}\right)^{\frac{\gamma}{1-\gamma}}$. Hence, $\left[R_{J}(\mathbf{e})-C_{a}\left(e_{a}\right)-C_{b}\left(e_{b}\right)\right] / r>V_{H, S}(\bar{k})$ and so $\hat{x}$ is infinite. This contradicts the previously proved fact that $\hat{x}$ is finite. Therefore, $H$ is such that $\omega_{H}=\min \left\{\omega_{a} ; \omega_{b}\right\}$.

Proof of Propositions 3 and 4. Using (63) and (64) we can write the analogue to (65) 


$$
V_{i, J}(x(t))=\max _{\left.e_{i}\right|_{t=0}, \hat{x}_{i}}\left\{\frac{\left[\phi_{i} R_{J}(\mathbf{e})-C_{i}\left(e_{i}\right)\right]}{r}\left\{1-\left[\frac{x(t)}{\hat{x}}\right]^{\xi}\right\}+V_{i}^{*}\left(k_{H}(\hat{t})\right)\left[\frac{x(t)}{\hat{x}}\right]^{\xi}\right\},
$$

with $\hat{x} \equiv \min \left\{\hat{x}_{a} ; \hat{x}_{b}\right\}$.

Proceeding backwards in time, we first characterize each partner's privately optimal dissolution time. Given that $k_{H}\left(\hat{t}_{i}\right)=\bar{k}-\left[\bar{k}-k_{H}(0)\right]\left(1-f_{H}\right) /\left(\hat{x}_{i}-f_{H}\right)$, we have $\partial / \partial \hat{x}_{i}\left[k_{H}\left(\hat{t}_{i}\right)\right]=\left[\bar{k}-k_{H}\left(\hat{t}_{i}\right)\right] /\left(\hat{x}_{i}-f_{H}\right)$. Differentiating (71) w.r.t. $\hat{x}_{i}$, we have

$$
\begin{aligned}
\frac{\partial V_{i, J}(x(t))}{\partial \hat{x}_{i}}=\frac{1}{\hat{x}_{i}\left(\hat{x}_{i}-f_{H}\right)}\left[\frac{x(t)}{\hat{x}_{i}}\right]^{\xi}\left\{\xi\left(\hat{x}_{i}-f_{H}\right) \frac{\left[\phi_{i} R_{J}(\mathbf{e})-C_{i}\left(e_{i}\right)\right]}{r}\right. & \\
& \left.-\left[\hat{x}_{i}+\xi\left(\hat{x}_{i}-f_{H}\right)\right] V_{i}^{*}\left(k_{H}\left(\hat{t}_{i}\right)\right)+\hat{x}_{i} V_{i}^{*}(\bar{k})\right\} .
\end{aligned}
$$

Given that $V_{i}^{*}\left(k\left(\hat{t}_{i}\right)\right)<V_{i}^{*}(\bar{k})$, the f.o.c. for $\hat{x}_{i}$ yields

$$
F\left(\hat{x}_{i}\right)=\left(\frac{1-f_{H}}{\xi}\right) \frac{\psi_{i}^{H} V_{H, S}\left(\bar{k}-k_{H}(0)\right)}{\left\{V_{i}^{*}(\bar{k})-\left[\phi_{i} R_{J}(\mathbf{e})-C_{i}\left(e_{i}\right)\right] / r\right\}},
$$

where

$$
F\left(\hat{x}_{i}\right) \equiv \frac{\left(\hat{x}_{i}-f_{H}\right)^{2}}{(1+\xi) \hat{x}_{i}-\xi f_{H}}
$$

if $\left[\phi_{i} R_{J}(\mathbf{e})-C_{i}\left(e_{i}\right)\right] / r<V_{i}^{*}(\bar{k})$ and $\hat{x}_{i} \rightarrow+\infty$ otherwise. A necessary condition for the contract $\phi_{i}$ and $\left(\psi_{i}^{0}, \psi_{i}^{H}\right)$ to be renegotiation proof is that the two partners' privately optimal dissolution times coincide: $\hat{t}_{a}=\hat{t}_{b}$. This is equivalent to $\hat{x}_{a}=\hat{x}_{b}$. Using (73), this is in turn equivalent to

$$
\psi_{i}^{0}=\frac{\left[\phi_{i} R_{J}(\mathbf{e})-C_{i}\left(e_{i}\right)\right]}{r}-\psi_{i}^{H} \frac{\left[R_{J}(\mathbf{e})-C_{a}\left(e_{a}\right)-C_{b}\left(e_{b}\right)\right]}{r} .
$$

We then determine the partners' resource contributions. Using the Envelope Theorem, we have $d V_{i, J}(x(t)) / d e_{i}=\partial\left[\phi_{i} R_{J}(\mathbf{e})-C_{i}\left(e_{i}\right)\right] / \partial e_{i}\left\{1-\left[\frac{x(t)}{\hat{x}}\right]^{\xi}\right\}$, and the f.o.c. for $e_{i}$ directly yields (39). With (39) for partner $a$ and partner $b$, we obtain (38). With (39) we also obtain

$$
\phi_{i} R_{J}(\mathbf{e})-C_{i}\left(e_{i}\right)=\phi_{i}\left(1-\gamma \delta_{i}\right) s(\mathbf{e})^{\gamma} \bar{k}^{1-\gamma} .
$$

With (76) and (71), we obtain (37). Also, using (73), (75), and (76), we have that $\hat{x}$ can be written as in (42), where $A_{i}(X)$ and $G_{i}(X)$ are defined in (26) and (28), respectively, and $\Delta$ is given by (41). Using $k_{i}(\hat{t})=\bar{k}-\left[\bar{k}-k_{H}(0)\right]\left(1-f_{i}\right) /\left(\hat{x}-f_{H}\right)$, (19), and (42), we obtain $k_{i}(\hat{t})$ given in (40). The identity of $H$ then follows.

We now show by contradiction that $\hat{x}$ is always finite: Assume that $\hat{x} \rightarrow+\infty$. Then $\left.k_{i}(t)\right|_{t \rightarrow+\infty}=\bar{k}$. It follows that $\left.S_{i}(t)\right|_{t \rightarrow+\infty}=\left(\omega_{j} / \omega_{i}\right)^{\gamma / 1-\gamma}$. Hence, the superior user of the asset at dissolution, $H$, is such that $\omega_{H}=\min \left\{\omega_{a} ; \omega_{b}\right\}$ in case of very late dissolution. Now, with (76), $\left[R_{J}(\mathbf{e})-C_{a}\left(e_{a}\right)-C_{b}\left(e_{b}\right)\right] / r<V_{H, S}(\bar{k})$ when 


$$
\frac{\omega_{H}}{\omega_{L}}<\Delta^{-\frac{1}{\delta_{L}}}
$$

Given that the profit ratio under the first- and second-best is

$$
R_{\text {first } / \text { second }} \equiv \frac{\left.\left[R_{J}(\mathbf{e})-C_{a}\left(e_{a}\right)-C_{b}\left(e_{b}\right)\right]\right|_{\text {first-best }}}{\left.\left[R_{J}(\mathbf{e})-C_{a}\left(e_{a}\right)-C_{b}\left(e_{b}\right)\right]\right|_{\text {second-best }}} \geq 1
$$

and that, with (69) and (76), we have $R_{\text {first } / \text { second }}=(1 / \Delta)^{\gamma / 1-\gamma}$, it follows that $\Delta \leq 1$. But if $\omega_{H}=\min \left\{\omega_{a} ; \omega_{b}\right\}$, then (77) holds. Hence, $\left[R_{J}(\mathbf{e})-C_{a}\left(e_{a}\right)-C_{b}\left(e_{b}\right)\right] / r<V_{H, S}(\bar{k})$ and so $\hat{x}$ is finite, which is a contradiction. Therefore, $\hat{x}$ is always finite.

Unlike the case of Proposition 2, it is no longer the case that $H$ is always such that $\omega_{H}=\min \left\{\omega_{a} ; \omega_{b}\right\}$. Attempting to use the same proof by contradiction as in the proof of Proposition 2 above would require $\left[R_{J}(\mathbf{e})-C_{a}\left(e_{a}\right)-C_{b}\left(e_{b}\right)\right] / r=$ $\frac{\bar{k}}{r}\left(1-\phi_{a} \delta_{a} \gamma-\phi_{b} \delta_{b} \gamma\right)\left(\phi_{a}^{\delta_{a}} \phi_{b}^{\delta_{b}}\right)\left(\gamma / \omega_{a}^{\delta_{a}} \omega_{b}^{\delta_{b}}\right)^{\frac{\gamma}{1-\gamma}}$ to be smaller than $V_{H, S}(\bar{k})=$ $\frac{\bar{k}}{r}(1-\gamma)(\gamma \max \{\omega-a ; \omega-b\})^{\frac{\gamma}{1-\gamma}}$. However, there is no clear ranking of $\left[R_{J}(\mathbf{e})-C_{a}\left(e_{a}\right)-C_{b}\left(e_{b}\right)\right] / r$ and $V_{H, S}(\bar{k})$, as was the case in the proof of Proposition 2. Thus, it is possible for either partner to be the superior user at dissolution, depending on whether $\left.S_{a}(\hat{t})\right|_{H=a}$ in (43) is greater or smaller than 1 .

Finally, we derive the second-best sharing rule, $\phi_{i}$, and the optimal exit rule, $\left(\psi_{i}^{0}, \psi_{i}^{H}\right)$. Recall that $\phi_{a}+\phi_{b}=1, \psi_{a}^{0}+\psi_{b}^{0}=0$, and $\psi_{a}^{H}+\psi_{b}^{H}=1$. The total value of the joint venture is therefore $W_{J}(x(t))=V_{a, J}(x(t))+V_{b, J}(x(t))$. It is also the case that $V_{a}^{*}(k(\hat{t}))+V_{b}^{*}(k(\hat{t}))=V_{H, S}(k(\hat{t}))$. Using the Envelope Theorem, we have $d W_{J}(x(t)) / d \phi_{i}=\partial\left[R_{J}(\mathbf{e})-C_{a}\left(e_{a}\right)-C_{b}\left(e_{b}\right)\right] / \partial \phi_{i}\left\{1-[x(t) / \hat{x}]^{\xi}\right\}$. From (75), we have

$$
\frac{\partial\left[R_{J}(\mathbf{e})-C_{a}\left(e_{a}\right)-C_{b}\left(e_{b}\right)\right]}{\partial \phi_{i}}=\left[\frac{\left(1-\phi_{a} \delta_{a} \gamma-\phi_{b} \delta_{b} \gamma\right)}{(1-\gamma)}\left(\frac{\delta_{i}}{\phi_{i}}-\frac{\delta_{j}}{\phi_{j}}\right)-\left(\delta_{i}-\delta_{j}\right)\right] \gamma s(\mathbf{e})^{\gamma} \bar{k}^{1-\gamma} .
$$

Solving for $\phi_{i}$ and $\phi_{j}$, we obtain the sharing rule (33). We then have $\partial\left[R_{J}(e)-C_{a}\left(e_{a}\right)-C_{b}\left(e_{b}\right)\right] / \partial \psi_{i}^{H}=0$, so $d W_{J}(x(t)) / d \psi_{i}^{H}=0$. Therefore, a contract $\phi_{i}$ and $\left(\psi_{i}^{0}, \psi_{i}^{H}\right)$ maximizes $W_{J}(x(t))$ and is renegotiation proof if it satisfies (33) and (75). Now, with (76) and (38), (75) can be written as (35).

The payoffs from the CCM. We consider a slightly more general form of the CCM, which allows for payments $\psi_{i}^{0}$ and $\psi_{j}^{0}=-\psi_{i}^{0}$ received by partners $i$ and $j$, respectively. Under the CCM, partner $j$ chooses an exit price $W^{\mathrm{CCM}}$ at the time of dissolution. Partner $i$ can then either (i) buy out partner $j$ for $\phi_{j} W^{\mathrm{CCM}}$ or (ii) sell out to partner $j$ for $\phi_{i} W^{\mathrm{CCM}}$. The values to partner $i$, including the fixed payments, are then $V_{i, S}\left(k_{i}(\hat{t})\right)+\psi_{i}^{0}-\phi_{j} W^{\mathrm{CCM}}$ when buying out partner $j$ and $\psi_{i}^{0}+\phi_{i} W^{\mathrm{CCM}}$ when selling out to partner $j$.

If $V_{i, S}\left(k_{i}(\hat{t})\right) \geq V_{j, S}\left(k_{j}(\hat{t})\right)$, partner $j$ best chooses an exit price

$$
W^{\mathrm{CCM}}=V_{i, S}\left(k_{i}(\hat{t})\right)
$$

In this case, partner $i$ chooses to buy out partner $j$ and 


$$
\begin{aligned}
& V_{i}^{*}\left(k_{i}(\hat{t})\right)=\psi_{i}^{0}+\phi_{i} W^{\mathrm{CCM}}, \\
& V_{j}^{*}\left(k_{i}(\hat{t})\right)=\psi_{j}^{0}+\phi_{j} W^{\mathrm{CCM}} .
\end{aligned}
$$

If $V_{i, S}\left(k_{i}(\hat{t})\right)<V_{j, S}\left(k_{j}(\hat{t})\right)$, partner $j$ chooses an exit price

$$
W^{\mathrm{CCM}}=V_{i, S}\left(k_{i}(\hat{t})\right) \text {. }
$$

In this case, partner $i$ chooses to sell out to partner $j$ and

$$
\begin{gathered}
V_{i}^{*}\left(k_{j}(\hat{t})\right)=\psi_{i}^{0}+\phi_{i} W^{\mathrm{CCM}}, \\
V_{j}^{*}\left(k_{j}(\hat{t})\right)=\psi_{j}^{0}+V_{j, S}\left(k_{j}(\hat{t})\right)-\phi_{i} W^{\mathrm{CCM}} .
\end{gathered}
$$

Partner $j$ 's best choice is therefore always to choose an exit price $W^{\mathrm{CCM}}=V_{i, S}\left(k_{i}(\hat{t})\right)$. The payoffs to partners $i$ and $j$ are therefore

$$
V_{j}^{*}\left(k_{H}(\hat{t})\right)=\left\{\begin{array}{cc}
V_{j}^{*}\left(k_{H}(\hat{t})\right)=\phi_{j}^{0}+\phi_{i, S} V_{i, S}\left(k_{i}(\hat{t})\right) \quad \text { if } V_{i, S}\left(k_{i}(\hat{t})\right) \geq V_{j, S}\left(k_{j}(\hat{t})\right), \\
\text { and partner } i \text { buys out partner } j ; \\
\psi_{j}^{0}+V_{j, S}\left(k_{j}(\hat{t})\right)-\phi_{i} V_{i, S}\left(k_{i}(\hat{t})\right) \quad \text { if } V_{i, S}\left(k_{i}(\hat{t})\right)<V_{j, S}\left(k_{j}(\hat{t})\right), \\
\text { and partner } i \text { sells out to partner } j .
\end{array}\right.
$$

Note that it is always the superior user of the asset at dissolution, partner $H$, who buys out its counterpart. From (86) and (87), the more general form of the CCM amounts to an exit rule

$$
\left(\psi_{i}^{0}, \psi_{i}^{H}\right),\left(\psi_{j}^{0}, \psi_{j}^{H}\right)= \begin{cases}\left(\psi_{i}^{0}, \phi_{i}\right),\left(\psi_{j}^{0}, \phi_{j}\right), & \text { if }(i, j)=(H, L) \\ \left(\psi_{i}^{0}, \phi_{i} \frac{V_{i, S}\left(k_{i}(t)\right)}{V_{j, S}\left(k_{j}(t)\right)}\right),\left(\psi_{j}^{0}, 1-\phi_{i} \frac{V_{i, S}\left(k_{i}(t)\right)}{V_{j, S}\left(k_{j}(t)\right)}\right) & \text { if }(i, j)=(H, L)\end{cases}
$$

Under the more usual form of the CCM, which does not allow for the payments $\psi_{i}^{0}$ and $\psi_{j}^{0}$, the exit rule is as above but with $\psi_{i}^{0}=\psi_{j}^{0}=0$.

Proof of Lemmas 1 and 2. For all $\chi \in\left\{r ; \mu ; \sigma^{2} / 2 ; \bar{k} ; k_{H}(0) ; k_{L}(0) ; f_{H} ; f_{L} ; \omega_{H} ; \omega_{L}\right\}$, we have $\operatorname{sign}(\partial \hat{t} / \partial \chi)=\operatorname{sign}\left(\partial \hat{x}_{J} / \partial \chi\right)$.

For $\chi \in\left\{r ; \mu ; \sigma^{2} / 2\right\}$, we have $\partial \hat{x}_{J} / \partial \chi=\partial \hat{x}_{J} / \partial \xi \partial \xi / \partial \chi$, and we establish

$$
\frac{\partial \hat{x}_{J}}{\partial \xi}=-\frac{\hat{x}_{J}}{\xi(1+\xi)\left[A_{H}(\Delta)-1\right]}<0 .
$$

The term $\xi$ is the positive root of $\xi^{2} \sigma^{2} / 2+\xi\left(\mu-\sigma^{2} / 2\right)-r=0$ and $\xi>1$. Let $\Theta \equiv\left(\mu-\sigma^{2} / 2\right)^{2}+2 \sigma^{2} r$. 
Then, using the fact that $\left(\xi \sigma^{2}+\mu-\sigma^{2} / 2\right)=\Theta^{1 / 2}$, we have

$$
\frac{\partial \xi}{\partial r}=\frac{1}{\Theta^{1 / 2}}>0, \quad \frac{\partial \xi}{\partial \mu}=-\frac{\xi}{\Theta^{1 / 2}}<0, \text { and } \quad \frac{\partial \xi}{\partial\left(\sigma^{2} / 2\right)}=-\frac{\xi(\xi-1)}{\Theta^{1 / 2}}<0 .
$$

Therefore, $\partial \hat{x}_{J} / \partial r<0, \partial \hat{x}_{J} / \partial \mu>0$, and $\partial \hat{x}_{J} / \partial\left(\sigma^{2} / 2\right)>0$.

Using (41), for $\chi \in\left\{\bar{k} ; k_{H}(0) ; k_{L}<(0) ; f_{L} ; \omega_{H} ; \omega_{L}\right\}$, we have $\partial \Delta / \partial \chi=0$.

Using (27), we have $\partial B(\Delta) / \partial \chi=0$ for $\chi \in\left\{\bar{k} ; k_{H}(0) ; k_{L}(0) ; f_{L}\right\}, \partial B(\Delta) / \partial \omega_{H}<0$, and $\partial B(\Delta) / \partial \omega_{L}>0$.

Using (28), we then have $\partial G_{H}(\Delta) / \partial \bar{k}>0, \partial G_{H}(\Delta) / \partial k_{H}(0)<0, \partial G_{H}(\Delta) / \partial k_{L}(0)=0$, $\partial G_{H}(\Delta) / \partial f_{H}<0, \partial G_{H}(\Delta) / \partial \omega_{H}>0$, and $\partial G_{H}(\Delta) / \partial \omega_{L}<0$.

From (26) and (42), $\hat{x}_{J}=(1+\xi) G_{H}(\Delta)+\sqrt{(1+\xi)^{2} G_{H}^{2}(\Delta)+2 f_{H} G_{H}(\Delta)}+f_{H}$. We therefore have $\partial \hat{x}_{J} / \partial \bar{k}>0, \partial \hat{x}_{J} / \partial k_{H}(0)<0, \partial \hat{x}_{J} / \partial k_{L}(0)=0, \partial \hat{x}_{J} / \partial f_{L}=0, \partial \hat{x}_{J} / \partial \omega_{H}>0$, and $\partial \hat{x}_{J} / \partial \omega_{L}<0$.

For $f_{H}$, from (5) and (6) we have $\partial k_{H}(t) / \partial f_{H}=g_{H}(t) /\left(x(t)-f_{H}\right)>0$ and $\partial k_{L}(t) / \partial f_{H}=0 . \quad$ So $\quad \partial V_{i}^{*}\left(k_{H}(t)\right) / \partial f_{H}=\psi_{i}^{H} V_{H, S}\left(g_{H}(t)\right) /\left(x(t)-f_{H}\right)>0 \quad$ whereas $\partial\left[\phi_{i} R_{J}(e)-C_{i}\left(e_{i}\right)\right] / \partial f_{H}=0$, for $i \in\{a, b\}$. Therefore from (71), we have $\partial \hat{x}_{i} / \partial f_{H} \leq 0$, for $i \in\{a, b\}$. Hence, $\partial \hat{x}_{J} / \partial f_{H} \leq 0$.

\section{References}

Allen, J., and G. M. Phillips, 2000, "Corporate Equity Ownership, Strategic Alliances, and Product Market Relationships,” Journal of Finance, 55, 2791-2815.

Anderson, R. W., and S. Sundaresan, 1996, "Design and Valuation of Debt Contracts," Review of Financial Studies, 9, 37-68.

Ariño, A. and J. de la Torre, 1998, "Learning from Failure: Towards an Evolutionary Model of Collaborative Ventures," Organization Science, 9, 306-325.

Artzner, Ph., and F. Delbaen, 1989, "Term Structure of Interest Rates: The Martingale Approach," Advances in Applied Mathematics, 10, 95-129.

Belleflamme, P., and F. Bloch, 2000, "Optimal Ownership Structures in Asymmetric Joint Ventures," Working Paper, Queen Mary and Westfield College.

Berk, J. B., R. C. Green, and V. Naik, 2004, "Valuation and Return Dynamics of New Ventures," Review of Financial Studies, 17, 1-35.

Berg, S. V., and P. Friedman, 1977, "Joint Ventures, Competition, and Technological Complementarities: Evidence from Chemicals," Southern Economic Journal, 43, 1330-1337.

Bergemann, D., and U. Hege, 2005, “The Financing of Innovation: Learning and Stopping," Rand Journal of Economics, 36, 719-752.

Bhattacharyya, S., and F. Lafontaine, 1995, "Double-Sided Moral Hazard and the Nature of Share Contracts," Rand Journal of Economics, 26, 761-781.

Bleeke, J., and D. Ernst, 1995, "Is Your Strategic Alliance Really a Sale?" Harvard Business Review, January-February, 97-105.

Bruner, R. F., 1999, “An Analysis of Value Destruction and Recovery in the Alliance and Proposed Merger of Volvo and Renault," Journal of Financial Economics, 51, 125-166. 
Chan, S. H., J. W. Kensinger, A. J. Keown, and J. D. Martin, 1997, "Do Strategic Alliances Create Value?" Journal of Financial Economics, 46, 199-221.

Chang, G., and S. Sundaresan, 2001, "A Model of Dynamic Sovereign Borrowing Effects of Credit History and Sanctions,” Working Paper, Columbia University.

Chemla, G., M. A. Habib, and A. Ljungqvist, 2004, “An Analysis of Shareholder Agreements,” forthcoming in Journal of the European Economic Association.

Collin-Dufresne, P., R. S. Goldstein, and S. J. Martin, 2001, "The Determinants of Credit Spread Changes," Journal of Finance, 56, 2177-2207.

Collis, D. J., and C. A. Montgomery, 1998, Corporate Strategy, Irwin McGraw-Hill, Boston.

Cox, D., and H. D. Miller, 1984, The Theory of Stochastic Processes, Science Paperbacks, New York.

Cramton, P., R. Gibbons, and P. Klemperer, 1987, “Dissolving a Partnership Efficiently,” Econometrica, $55,615-632$.

Crawford, V. P., and W. P. Heller, 1979, "Fair Division with Indivisible Commodities," Journal of Economic Theory, 21, 10-27.

Darrough, M. N., and N. M. Stoughton, 1989, “A Bargaining Approach to Profit Sharing in Joint Ventures," Journal of Business, 62, 237-270.

Doz, Y. L., 1996, "The Evolution of Cooperation in Strategic Alliances: Initial Conditions or Learning Processes," Strategic Management Journal, 17, 55-83.

Doz, Y. L., and G. Hamel, 1998, Alliance Advantage, Harvard Business School Press, Boston.

Dyer, J. H., P. Kale, and H. Singh, 2004, "When to Ally and When to Acquire," Harvard Business Review, July-August, 109-115.

Elfenbein, D., and J. Lerner, 2003, "Ownership and Control Rights in Internet Portal Alliances, 19951999," Rand Journal of Economics, 34, 356--369.

Fan, H., and S. Sundaresan, 2000, "Debt Valuation, Renegotiation, and Optimal Dividend Policy," Review of Financial Studies, 13, 1057-1099.

Fluck, Z., K. Garrison, and S. C. Myers, 2005, "Venture Capital Contracting and Syndication: An Experiment in Computational Corporate Finance," NBER Working Paper No. 11624.

Fluck, Z., and A. W. Lynch, 1999, "Why Do Firms Merge and Then Divest? A Theory of Financial Synergy,” Journal of Business, 72, 319-346.

Gomes, A., and W. Novaes, 2001, "Sharing of Control as a Corporate Governance Mechanism," Working Paper, Wharton School, University of Pennsylvania.

Hackbarth, D., C. A. Hennessy, and H. E. Leland, 2004, "Can the Tradeoff Theory Explain Debt Structure," Working Paper, University of California, Berkeley.

Hamel, G., 1991, "Competition for Competence and Interpartner Learning within International Strategic Alliances,” Strategic Management Journal, 12, 83-103.

Hart, O., 1995, Firms, Contracts, and Financial Structure, Oxford University Press, Oxford.

Hauswald, R., and U. Hege, 2003, "Ownership and Control in Joint Ventures: Theory and Evidence," Working Paper, HEC Paris.

Hennart, J.-F., T. Roehl, and D. S. Zietlow, 1999, “'Trojan Horse' or 'Workhorse'? The Evolution of U.S.-Japanese Joint Ventures in the United States," Strategic Management Journal 20, 15-29.

Holmström, B., 1982, "Moral Hazard in Teams,” Bell Journal of Economics, 13, 324- 40. 
Huang, J., and M. Huang, 2002, "How Much of the Corporate-Treasury Yield Spread is Due to Credit Risk? Results from a New Calibration Approach,” Working Paper, Stanford University.

Inkpen, A. C., and P. W. Beamish, 1997, "Knowledge, Bargaining Power and the Instability of International Joint Ventures,” Academy of Management Review, 22, 177-202.

Jarrow, R. A., and S. M. Turnbull, 1995, "Pricing Derivatives on Financial Securities Subject to Credit Risk," Journal of Finance, 50, 53-85.

Johnson, S. A., and M. B. Houston, 2000, "A Reexamination of the Motives and Gains in Joint Ventures," Journal of Financial and Quantitative Analysis, 35, 67-85.

Kaplan, S. N., and M. S. Weisbach, 1992, “The Success of Acquisitions: Evidence from Divestures,” Journal of Finance, 47, 107-138.

Khanna, T., R. Gulati, and N. Nohria, 1998, "The Dynamics of Learning Alliances: Competition, Cooperation, and Relative Scope,” Strategic Management Journal, 19, 193-210.

Kogut, B., 1989, “The Stability of Joint Ventures: Reciprocity and Competitive Rivalry,” Journal of Industrial Economics, 38, 183-198.

Kogut, B., 1991, “Joint Ventures and the Option to Expand and Acquire,” Management Science, 37, 1933.

Lambrecht, B. M., 2004, “The Timing and Terms of Mergers Motivated by Economies of Scale,” Journal of Financial Economics, 72, 41-62.

Lando, D., 1994, Three Essays on Contingent Claims Pricing, Ph.D. Thesis, Cornell University.

Legros, P., and S. A. Matthews, 1993, "Efficient and Nearly-Efficient Partnerships," Review of Economic Studies, 60, 599-611.

Leland, H. E., 1994, "Risky Debt, Bond Covenants and Optimal Capital Structure,” Journal of Finance, $49,1213-1252$.

Leland, H. E., 1998, “Agency Costs, Risk Management, and Capital Structure,” Journal of Finance, 53, $1213-1243$.

Leland, H. E., 2004, "Predictions of Default Probabilities in Structural Models of Debt," Journal of Investment Management, 2, 5-21.

Leland, H. E., and J. Skarabot, 2003, "On Purely Financial Synergies and the Optimal Scope of the Firm: Implications for Mergers, Spinoffs, and Structured Finance," forthcoming in Journal of Finance.

Leland, H. E., and K. B. Toft, 1996, "Optimal Capital Structure, Endogenous Bankruptcy, and the Term Structure of Credit Spreads,” Journal of Finance, 51, 987-1019.

Makhija, M. V., and U. Ganesh, 1997, "The Relationship between Control and Partner Learning in Learning-Related Joint Ventures,” Organization Science, 8, 508-527.

McAfee, R. P., 1992, “Amicable Divorce: Dissolving a Partnership with Simple Mechanisms,” Journal of Economic Theory, 56, 266-293.

McConnell, J. J., and T. J. Nantell, 1985, “Corporate Combinations and Common Stock Returns: The Case of Joint Ventures," Journal of Finance, 40, 519-536.

McDonald, R., and D. Siegel, 1986, "The Value of Waiting to Invest," Quarterly Journal of Economics, $101,707-727$.

Mella-Barral, P., 1999, "The Dynamics of Default and Debt Reorganization," Review of Financial Studies, 12, 535-578.

Mella-Barral, P., and W. R. M. Perraudin, 1997, "Strategic Debt Service," Journal of Finance, 52, 531-556. 
Minehart, D., and Z. Neeman, 1999, “Termination and Coordination in Partnerships," Journal of Economics and Management Strategy, 8, 191-221.

Mohanram, P., and A. Nanda, 1998, "When Do Joint Ventures Create Value?" Working Paper, Harvard Business School.

Morellec, E., 2004, “Can Managerial Discretion Explain Observed Leverage Ratios?” Review of Financial Studies, 17, 257-294.

Morellec, E., and A. Zhdanov, 2005, “The Dynamics of Mergers and Acquisitions,” Journal of Financial Economics, 77, 649-672.

Muennich, F., 2000, "Spillovers, Knowledge Disclosure and Innovation," Working Paper, London School of Economics.

Myerson, R. B., 1997, Game Theory: Analysis of Conflict, Harvard University Press, Cambridge, MA.

Nanda, A., and P. J. Williamson, 1995, "Use Joint Ventures to Ease the Pain of Restructuring," Harvard Business Review, November-December, 119-128.

Noe, T. H., M. J. Rebello, and M. M. Shrikhande, 2002, "Structuring International Joint Ventures," Review of Financial Studies, 15, 1251-1282

Oxley, J. E., 1997, “Appropriability Hazards and Governance in Strategic Alliances: A Transaction Cost Approach," Journal of Law, Economics, and Organization, 13, 387-409.

Park, S. H., and M. V. Russo, 1996, "When Competition Eclipses Cooperation: An Event History Analysis of Joint Venture Failure," Management Science, 42, 875-890.

Pisano, G., 1989, "Using Equity Participation to Support Exchange: Evidence from the Biotechnology Industry," Journal of Law, Economics, and Organization, 5, 109-126.

Prahalad, C. K., and G. Hamel, 1990, "The Core Competence of the Corporation," Harvard Business Review, May-June, 79-91.

Reich, R. B., and E. D. Mankin, 1986, "Joint Ventures with Japan Give Away our Future," Harvard Business Review, March-April, 78-85.

Reuer, J. J., 2001, "From Hybrids to Hierarchies: Shareholder Wealth Effects of Joint Venture Partner Buyouts,” Strategic Management Journal, 22, 27-44.

Reuer, J. J., M. Zollo, and H. Singh, 2002, “Post-Formation Dynamics in Strategic Alliances,” Strategic Management Journal, 23, 135-151.

Rey, P., and J. Tirole, 1998, "Divergence of Objectives and the Governance of Joint Ventures," Working Paper, IDEI.

Sampson, R. C., 2004, "The Cost of Misaligned Governance in R\&D Alliances," Journal of Law, Economics, and Organization, 20, 484-526.

Sundaresan, S., 2000, "Continuous-Time Methods in Finance: A Review and an Assessment," Journal of Finance, 55, 1569-1622.

Van den Steen, E., 2002, "Equity Participations, Hold-Up, and Firm Boundaries," Working Paper 435202 MIT Sloan School of Management. 